\title{
RMetS
}

Royal Meteorological Society

\section{Adjustment of the atmospheric circulation to tropical Pacific SST anomalies: Variability of transient eddy propagation in the Pacific-North America sector ${ }^{\dagger}$}

\author{
R. Seager, ${ }^{a \star}$ N. Naik, ${ }^{a}$ M. Ting, ${ }^{a}$ M. A. Cane, ${ }^{a}$ N. Harnik ${ }^{b}$ and Y. Kushnir ${ }^{a}$ \\ ${ }^{a}$ Lamont Doherty Earth Observatory of Columbia University, Palisades, NY, USA \\ ${ }^{\mathrm{b}}$ Department of Geophysics and Planetary Sciences, Tel Aviv University, Tel Aviv, Israel \\ ${ }^{\star}$ Correspondence to: R. Seager, Lamont Doherty Earth Observatory of Columbia University, Palisades, New York 10964, \\ USA. E-mail: seager@ldeo.columbia.edu \\ ${ }^{\dagger}$ Lamont Doherty Earth Observatory Contribution Number X.
}

\begin{abstract}
El Niño-Southern Oscillation (ENSO) related precipitation anomalies in North America are related to changes in the paths of storm systems across the Pacific Ocean, with a more southern route into southwestern North America during El Niños and a more northern route into the Pacific Northwest during La Niñas. Daily reanalysis data are analyzed to confirm these changes. Seasonal mean upper tropospheric eddy statistics show, for El Niños (La Niñas), a pattern that is shifted southward (northward) compared with climatology. Paths of coherent phase propagation of transient eddies and of the propagation of wave packets are analyzed. A coherent path of propagation across the Pacific towards North America is identified that is more zonal during El Niño winters and, during La Niñas, has a dominant path heading northeastward to the Pacific Northwest. A second path heading southeastward from the central Pacific to the tropical east Pacific is more accentuated during La Niñas than El Niños. These changes in wave propagation are reproduced in an ensemble of seasonal integrations of a general circulation model forced by a tropical Pacific sea-surface temperature pattern, confirming that the changes are forced by changes in the mean atmospheric state arising from changes in tropical sea-surface temperature. A simplified model with a specified basic state is used to model the storm tracks for El Niño and La Niña winters. The results suggest that the changes in transient eddy propagation and the eddy statistics can be understood in terms of the refraction of transient eddies within different basic states. Copyright (C) 2010 Royal Meteorological Society
\end{abstract}

Key Words: ENSO; transient eddy-mean-flow interaction

Received 5 February 2009; Revised 18 December 2009; Accepted 22 December 2009; Published online in Wiley InterScience 9 February 2010

Citation: Seager R, Naik N, Ting M, Cane MA, Harnik N, Kushnir Y. 2010. Adjustment of the atmospheric circulation to tropical Pacific SST anomalies: Variability of transient eddy propagation in the Pacific-North America sector. Q. J. R. Meteorol. Soc. 136: 277-296. DOI:10.1002/qj.588

1. Introduction

The El Niño-Southern Oscillation (ENSO) exerts a powerful influence on precipitation around the world (Ropelewski and Halpert, 1987, 1989, 1996; Kiladis and Diaz, 1989;
Seager et al., 2005a) and is the basis of most skill in seasonal to interannual prediction. Over North America, wintertime El Niño events tend to make the southern United States and Mexico wet from the Pacific to the Atlantic while the northwest United States and western Canada tend to be drier 
than normal. The opposite phase of ENSO, La Niña, tends to cause an opposite-signed precipitation anomaly pattern and, when it extends for years in a row, is responsible for the serious multiyear droughts that afflict southwestern North America (Schubert et al., 2004a, 2004b; Seager et al., 2005b, 2008a; Herweijer et al., 2006; Cook et al., 2007; Seager, 2007). ENSO-related precipitation anomalies over the Pacific and North America are often thought to be related to changes in the Pacific storm track with, during El Niño, a more southward-displaced and eastward-extended storm track and jet stream over the eastern Pacific (Hoerling and Ting, 1994; Trenberth and Hurrell, 1994; Straus and Shukla, 1997; Zhang and Held, 1999; Compo and Sardeshmukh, 2004; Orlanski, 2005; Chang, 2006; Eichler and Higgins, 2006) that brings storms into the southwest. Consistently, Seager et al. (2005a) used reanalysis data to show that during El Niño winters the subtropical jets in both hemispheres and patterns of low-level eddy meridional velocity variance and upper-level eddy momentum flux are all displaced equatorward.

Those results are suggestive of ENSO being able to orchestrate a rearrangement of the atmospheric eddy and mean flows. Both Straus and Shukla (1997) and Orlanski (2005) argue that the southward-displaced and eastwardextended storm track over the eastern Pacific during El Niños arises from increased baroclinic instability in that region that follows from the direct response of the atmospheric temperature and circulation to the central and eastern tropical Pacific heating anomalies (Trenberth et al., 1998). Orlanski (2005) and Shapiro et al. (2001) also argued for the possible importance of differences in nonlinear wave breaking during the different phases of the ENSO cycle. These authors recognize that these changes will in turn alter the mean flow and have a subsequent impact on wave propagation. Focusing more closely on paths of wave propagation, Seager et al. (2003, 2005a) argued for the following explanation: during an El Niño, tropical tropospheric warming increases the temperature gradient at around $15-20^{\circ}$ of latitude and, to maintain thermal wind balance, the subtropical jet strengthens here equatorward of its climatological maximum. Over the east and central Pacific Ocean the strengthening and equatorward shift of the jet is augmented by the Gill (1980) type response to anomalous convective heating over the anomalously warm waters of the central and eastern equatorial Pacific Ocean. The Gill response to heating has upper-level anticyclones straddling the Equator with anomalous westerlies on their poleward flanks, but again equatorward of the climatological jet at those longitudes. The altered upper-level mean flow in the Subtropics impacts the propagation of transient eddies so that during El Niño they propagate further equatorward into the tropical upper troposphere, creating a positive anomaly of poleward eddy momentum flux there and a negative anomaly immediately poleward. Since, in the zonal mean, the convergence of the eddy momentum flux is balanced by the Coriolis torque operating on the mean meridional flow, this requires equatorward flow at upper levels into the Tropics, forcing ascent in the midlatitudes. The eddyforced ascent, it is argued, causes tropospheric cooling and increased precipitation in midlatitudes during El Niños as observed. The same line of reasoning explains midlatitude drought during La Niña events.

Seager et al. (2003) used National Centers for Environmental Prediction-National Center for Atmospheric
Research (NCEP-NCAR) reanalysis data to make the case for the above means of tropical forcing of the mean circulation, and then reproduced the basics using a linear quasi-geostrophic model of transient eddy propagation. However, much remains to be done to prove that this mechanism of tropical modulation of midlatitude eddies (TMME) operates in the real atmosphere and is of relevance to ENSOforced precipitation anomalies. In particular, subtropical and midlatitude winter precipitation tends to occur in synoptic storms and, while the prior work demonstrated links between ENSO and time-averaged transient eddy statistics, it needs to be shown that the paths of transient eddies-midlatitude storms-are appreciably different during El Niño and La Niña. Further, the arguments advanced in the earlier studies imply a clear causality from tropical sea-surface temperature (SST) anomalies to changes in the tropical and subtropical mean flow to changes in eddy propagation and, finally, to changes in the eddy-driven mean flow. It is not possible to determine such cause and effect in observations, since the atmosphere is in quasi-equilibrium with the underlying slowly evolving SST anomalies, but it could potentially be demonstrated in controlled model experiments.

Here we attempt to fill in these gaps by studying the ENSO dependence of the propagation of synoptic eddies across the Pacific Ocean. We will do this using daily observations from the NCEP-NCAR reanalysis and daily data from short controlled integrations of a general circulation model (GCM). This work builds heavily on the work identifying propagating features developed by Chang and Yu (1999) and is also influenced by the analysis of the influence of the mean flow on wave propagation developed by Hoskins and Karoly (1981), Karoly (1983) and Hoskins and Ambrizzi (1993). The work also echoes prior work using storm-track models to examine the ENSO influence on the northern midlatitude storm tracks (Zhang and Held, 1999; Chang, 2006). We extend this prior work using the following approaches.

- Examining how ENSO-forced variations in the mean flow influence the paths of eddy propagation and the amplitude of wave packets as diagnosed from 59 years of reanalysis data. This will show that the timeaveraged changes in eddy statistics identified in prior work can be explained in terms of changes in eddy propagation paths.

- Examining whether the observed changes can be reproduced in a GCM forced only by changes in tropical Pacific SSTs.

- Determining whether these changes in the Pacific storm track can be reproduced in storm-track models when the basic state is imposed but changes in seeding and moist processes are ignored.

- Using basic states from differing time periods of a GCM forced by an instantaneous turn-on of tropical Pacific SST anomalies to determine whether changes in wave propagation can be discerned at times when tropical heating anomalies have forced mean-flow changes but before eddies strongly influence the mean flow.

It will be argued that ENSO-forced changes in the mean flow create different preferred routes-or waveguides-for transient eddy propagation that contribute to the southward shift and eastward extension of the storm track during El Niños. Increased generation of eddies in the central and east Pacific, or changes in storm-track seeding, may also 
be important, but the current work suggests that wave refraction is fundamental to ENSO-related changes in the North Pacific storm track.

While this work improves our diagnostic understanding of ENSO forcing of wave-mean-flow interaction in the Subtropics and midlatitudes, it only begins to address causality. In a follow-up article (Harnik et al., 2010) we will develop a causal account of tropical forcing of the mean flow, the impact on eddies and the subsequent feedback into the mean flow that constitutes a theory for the TMME mechanism.

\section{Data and models}

The observational analysis uses daily data from the NCEP-NCAR reanalysis (Kistler et al., 2001) covering the period 1949-2008. Here we focus on the December, January, February period when the Pacific storm track is strong and ENSO SST anomalies reach their peak strength. To isolate the ENSO impact, we identify December-February threemonth periods when the NINO3.4 index (SST averaged over $5^{\circ} \mathrm{S}-5^{\circ} \mathrm{N}, 170^{\circ} \mathrm{W}-130^{\circ} \mathrm{W}$ ) exceeds +1 (El Niño) or -1 (La Niña) standard deviations. These three-month intervals are then averaged together to create El Niño and La Niña composites of seasonal mean quantities. To examine transient eddy propagation, we examine the daily data within the identified El Niño and La Niña winters.

Statistical significance of the differences between El Niño and La Niña winters is assessed using a two-sided Student's $t$-test and statistics for all the winters within the reanalysis from 1949/50-2007/8. On the subsequent plots, where significance is shown, light shading indicates significance at the 95\% level and dark shading significance at the 99\% level. The large-scale patterns of all the observed anomalies shown here are significant at at least the 95\% level.

To determine that the identified circulation anomalies and transient eddy statistic anomalies during ENSO winters are indeed forced by tropical Pacific SSTs, we turn to 100 member ensembles of 100 day integrations with an atmospheric GCM, the NCAR Community Climate Model 3 (CCM3) (Kiehl et al., 1998). Each ensemble member begins on December 1 and runs for 100 days. Two 100 member ensembles are generated. The first has an El Niño SST anomaly immediately turned on on December 1 and held fixed for the subsequent 100 days. The anomaly stretches from $20^{\circ} \mathrm{S}-20^{\circ} \mathrm{N}$. The El Niño SST anomaly is the regression pattern of the tropical Pacific SSTs for December-February on the NINO3.4 SST index corresponding to $\mathrm{a}+1$ standard deviation of the index. This is the El Niño ensemble. The 'La Niña' ensemble has a La Niña SST anomaly, equal and opposite to the El Niño pattern, imposed on December 1 and held fixed for the next 100 days. $^{\dagger}$ We use 100

\footnotetext{
${ }^{\dagger}$ This means that the SST patterns used for the GCM experiments are not exactly the same as those associated with the observed El Niño minus La Niña differences. However, while this difference arose serendipitously because the model runs were completed (without the current analysis in mind) before the observational analysis was performed, it does allow a useful check on the nonlinearity of the atmosphere response to ENSO SST anomalies. The observational analyses contain any impact of a nonlinearity between El Niño and La Niña SST anomalies but the model results assume these are equal and opposite to each other. That the mode simulations do, to first order, reproduce the observed changes in eddy statistics implies that the SST anomaly nonlinearity is not crucial to the problem at hand.
}

different December 1 initial conditions generated from other runs of the model. The first ensemble members of the El Niño and La Niña ensembles start from the same initial condition, the second ensemble members of the ensembles start from a second, different, initial condition and so on. This means that over the time period of atmospheric predictability-about 10 days -the ensembles will differ primarily only by the imposition of different SSTs. Hence averaging across the 100 member ensemble isolates the day-to-day evolution of the transient and mean circulation in response to the imposed SST anomalies. After loss of atmospheric predictability, a 100 member ensemble is not large enough to isolate the forced response at the daily time-scale, but by time-averaging it is clearly visible again. To examine wave propagation, we use the daily data from each individual ensemble member. The evolution of the simulations is examined further in Harnik et al. (2010).

\section{Observational analysis of ENSO-related variability of transient eddy propagation in the Pacific-North America sector}

\subsection{ENSO-related changes in time-averaged eddy statistics}

The problem to be solved is concisely presented in Figures 1,2 and 3. Figure 1 shows the $300 \mathrm{mb}$ zonal wind for El Niño winters, La Niña winters and the difference. In El Niño winters a more zonal jet extends further east to southern North America. This amounts to a southwardshifted and eastward-extended jet stream compared with La Niña winters. Figure 2 shows maps of the transient eddy momentum flux $\overline{u^{\prime} v^{\prime}}$, where $u^{\prime}$ and $v^{\prime}$ are high-pass-filtered zonal and meridional velocities and the overbar denotes a low-pass filter. A fourth-order Butterworth filter with a 10 day cut-off is used to isolate variability with time-scales of less than 10 days. The low-pass-filtered data plus the high-pass-filtered data are equal to the original field. Figure 3 shows a corresponding map for $\overline{v^{\prime 2}}$. Figure 2 shows that during El Niño winters the region of positive values of $\overline{u^{\prime} v^{\prime}}$ moves southward over the central and eastern North Pacific, while the more northward region of negative values extends further east over the North Pacific and intensifies over the North Atlantic region. The maps of $\overline{v^{\prime 2}}$ (Figure 3) show a similar pattern, with the region of maximum values shifted south during El Niño winters. The continuity and zonality of the storm track from the Pacific to the Atlantic across southern North America is clearly evident in Figure 3. These patterns are consistent with an interpretation in terms of an equatorward shift of the storm track during El Niño and its extension eastward from the central Pacific into southern North America. It is evident that this is closely related to the canonical El Niño precipitation anomaly, with wetter than normal conditions across the southern United States and Mexico and drier than normal across the northern United States and Canada (Seager et al., 2005a). The question to be answered here is why this shift of the storm track occurs.

\subsection{Analysis of ENSO-related changes in transient eddy propagation across the North Pacific Ocean}

Next we back up our argument for a shift in the storm track by analyzing changes in the patterns of transient eddy propagation. Chang and Yu (1999) developed an elegant 

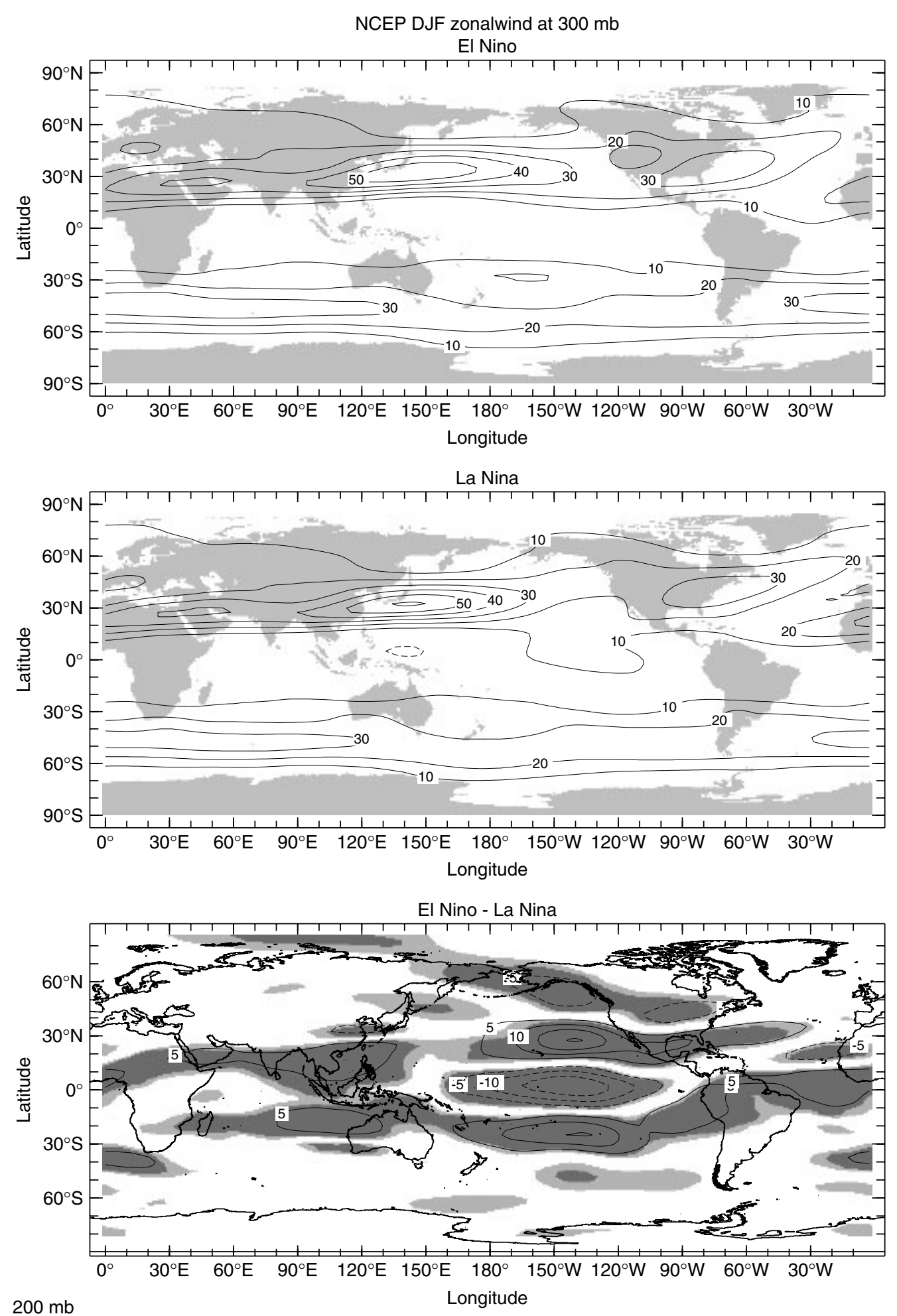

Figure 1. The $300 \mathrm{mb}$ zonal wind for El Niño winters (top), La Niña winters (middle) and the difference (bottom) as evaluated from the NCEP reanalysis. Light shading indicates significance at the $95 \%$ level and dark shading at the $99 \%$ level. Units are $\mathrm{m} \mathrm{s}^{-1}$.

means to determine preferred paths of transient eddy and wave-packet propagation, phase speeds and wave coherence. Their work concerned the climatological state and here we simply extend it to the El Niño and La Niña composites.

The Chang and Yu methodology begins with one-point correlation maps as shown in Figure 4. The value of $v^{\prime}$ at the $300 \mathrm{mb}$ level and at a chosen point in the centre of the Pacific storm track $\left(30^{\circ} \mathrm{N}, 180^{\circ} \mathrm{E}\right)$ is correlated with $v^{\prime}$ everywhere else at lags of $-2,-1,0,1$ and 2 days and for the
El Niño and La Niña composite winters separately. Looking first at zero lag, the one-point correlation map clearly shows a wave of zonal wave number 6 or 7 extending upstream and downstream from the central point. At negative lags the wave train is centred to the west and at positive lags to the east, indicating eastward propagation as expected. The location of maximum correlation also moves east with time confirming the appearance to the eye of a wave packet that propagates eastward. The wave packet moves considerably 

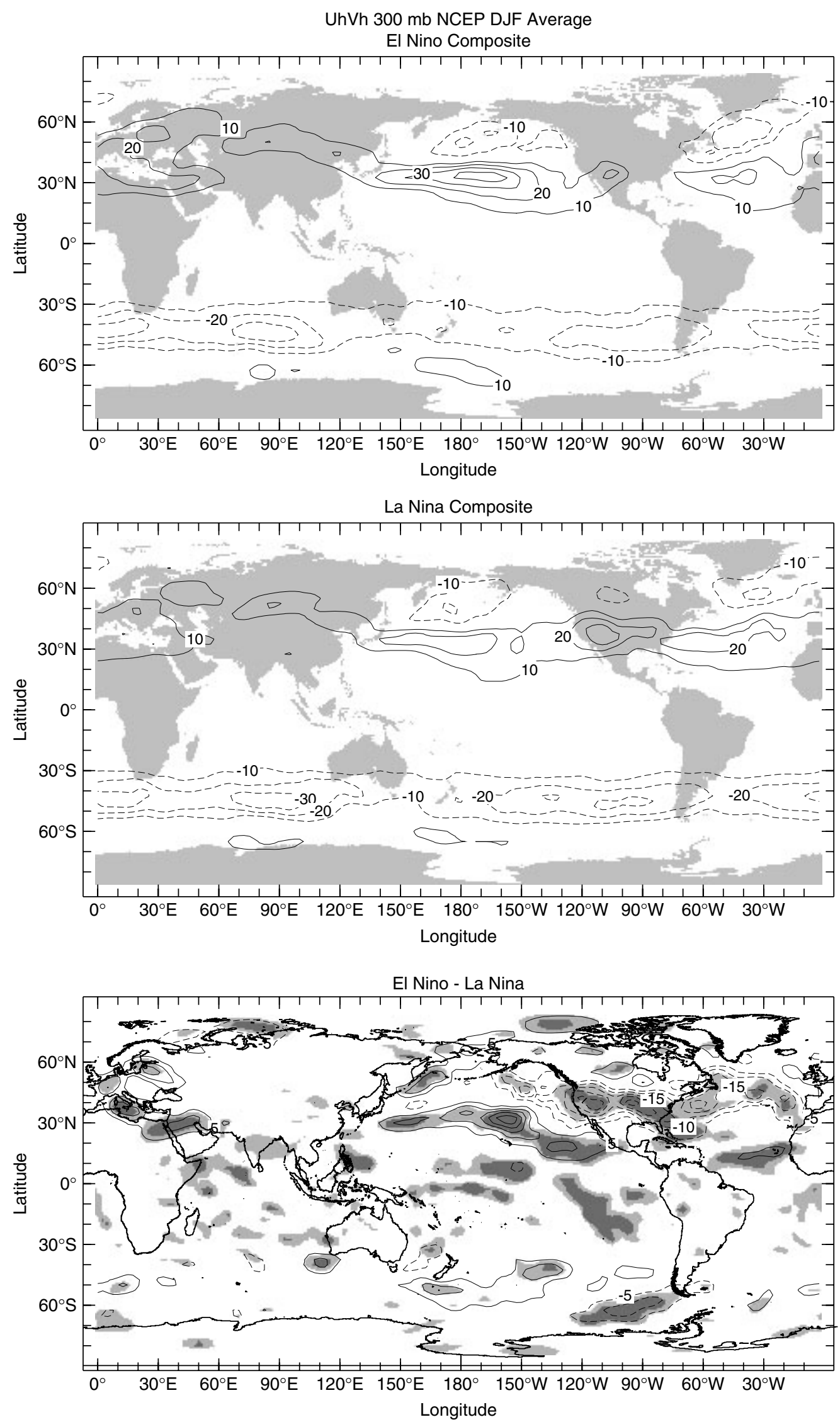

Figure 2. The transient eddy momentum flux $\overline{u^{\prime} v^{\prime}}$ at $300 \mathrm{mb}$ for El Niño winters (top), La Niña winters (middle) and the difference (bottom) as evaluated from the NCEP reanalysis. Shading for significance is as in Figure 1. Units are $\mathrm{m}^{2} \mathrm{~s}^{-2}$ and the contour interval is 5, with the zero contour suppressed. 

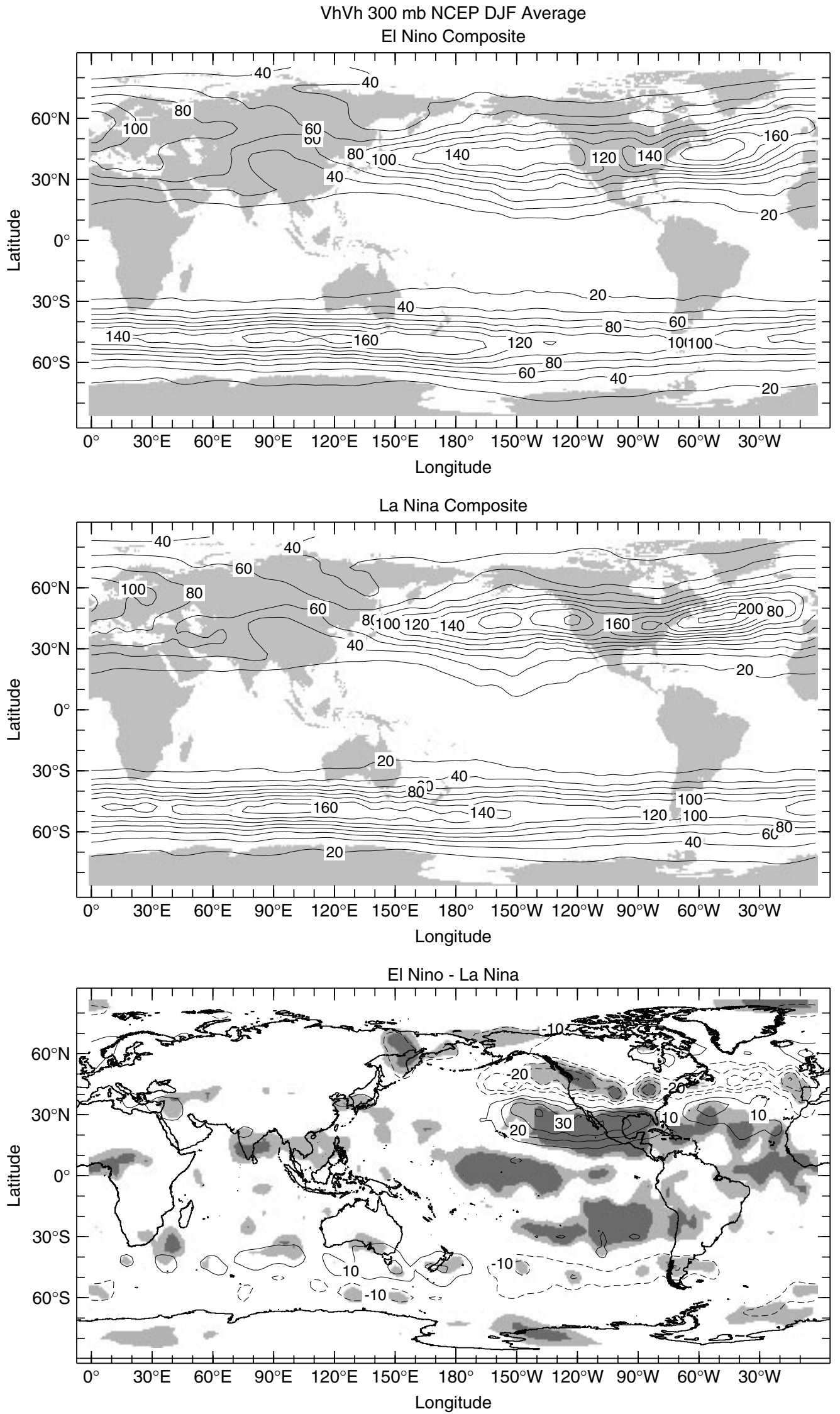

Figure 3. As for Figure 2 but for the transient eddy meridional velocity variance $\overline{v^{\prime 2}}$. 
faster eastward than the individual peaks and troughs-the phase speed. This illustrates downstream development of the disturbances (Chang and Yu, 1999).

These simple one-point correlation maps already suggest a difference between the El Niño case (left column) and the La Niña case (right column). The El Niño case shows propagation in a near-zonal direction from the central Pacific with, at lags 1 and 2, waves appearing over southern North America and moving across to the Gulf of Mexico and into the Atlantic sector. In contrast, during La Niña, at lags 1 and 2 there is more of a tendency of a split in the wave propagation with some energy moving into the Pacific Northwest region and some moving southeastward into the eastern tropical Pacific Ocean region and, relative to El Niño, less propagation into southern North America.

3.2.1. Using wave coherence indices to quantify changes in preferred paths of eddy propagation

The results from one-point correlation maps are of limited use because they depend to a large extent on the choice of base point. However, the information from all one-point correlation maps that use all the possible base points on the globe can be combined into an index at each point of wave coherence (the wave coherence index (WCI): Chang and $\mathrm{Yu}, 1999)$ which can be plotted.

The WCI is computed as follows. For each base point, the amplitude of the correlation at the nearest upstream centre at lag -2 and the amplitude at the nearest downstream centre at lag +2 are found and averaged together. The searching algorithim looks for the centres closest to the base point that are negatively correlated with the base point. The algorithim searches in both latitude and longitude to capture the arching nature of propagation seen in Figure 4. The average amplitude thus computed is the WCI at that base point. The procedure is repeated for all base points to provide maps of WCI. Regions of large WCI are places where waves -here identified in terms of phase propagation-propagate in a coherent manner. Results are shown in Figure 5.

In both El Niño and La Niña winters, the WCI is strongest in the Asian subtropical jet region and weakens eastward across the Pacific Ocean. For the El Niño winters the maximum of the WCI extends eastward across the Pacific-North America sector. In contrast, during the La Niña winters the WCI maximum extends northeastward towards the Pacific Northwest and western Canada. In addition there is another maximum of WCI that extends southeastward from the main storm track towards the eastern equatorial Pacific, which is stronger and further west in La Niña winters than in El Niño winters. These results are consistent with the impressions left by the single one-point correlation maps shown in Figure 4. However, by using all base points, the WCI results more clearly show the difference in preferred paths of transient eddy propagation across the North Pacific-North America region between El Niño and La Niña winters. For El Niño winters relatively more zonal phase propagation brings disturbances into southern North America. For La Niña winters there is a more northward propagation path that brings disturbances into the Pacific Northwest. Also, the southern route where disturbances 'leak' into the Tropics before reaching North America is stronger for La Niña winters. Despite these apparent changes, it should be noted that the changes in WCI are only about $10 \%$ of the mean values.

\subsubsection{ENSO-related changes in the propagation of wave packets}

The propagation of wave packets indicates the preferred paths of wave energy, which should be related to the precipitation associated with synoptic eddies. To track the propagation of wave packets, we follow Chang and $\mathrm{Yu}$ (1999) and assume that $v^{\prime}$ can be described in the form

$$
v^{\prime}(x, t)=\operatorname{Re}\left[A(x, t) \mathrm{e}^{\mathrm{i} k x}\right],
$$

where $k$ is a typical zonal wave number of transient eddies and $A(x, t)$ is an envelope function of the wave packet that varies slowly in space. We assume that $A$ has the form

$$
A(x, t)=A_{\mathrm{R}}(x, t) \mathrm{e}^{\mathrm{i} \phi},
$$

where $A_{\mathrm{R}}(x, t)$ is purely real. Hence

$$
\begin{aligned}
v^{\prime} & =\operatorname{Re}\left[A_{\mathrm{R}}(x, t) \mathrm{e}^{\mathrm{i}(k x+\phi)}\right] \\
& =\frac{1}{2} A_{\mathrm{R}}(x, t)\left(\mathrm{e}^{\mathrm{i}(k x+\phi)}+\mathrm{e}^{-\mathrm{i}(k x+\phi)}\right),
\end{aligned}
$$

so

$$
v^{\prime}(x, t) \mathrm{e}^{-\mathrm{i} k x}=\left[A_{\mathrm{R}}(x, t) / 2\right]\left(\mathrm{e}^{\mathrm{i} \phi}+\mathrm{e}^{-\mathrm{i}(2 k x+\phi)}\right) .
$$

The $2 k x$ in the second term ensures that that term has much smaller zonal spatial scales than the first term. Hence, after spatial smoothing to retain only low-wave-number contributions,

$$
v^{\prime}(x, t) \mathrm{e}^{-\mathrm{i} k x} \sim\left[A_{\mathrm{R}}(x, t) / 2\right] \mathrm{e}^{\mathrm{i} \phi}=A(x, t) / 2 .
$$

To accomplish the low pass that allows (6), we choose a $k$, Fourier transform $v^{\prime}(x, t) \mathrm{e}^{-\mathrm{i} k x}$ and retain only zonal wave numbers $0-6$. This determines $A(x, t)$ given $v^{\prime}$. The method used explicitly addresses only zonal variations and is used at all latitudes to derive an $A(x, t)$ at all longitudes and latitudes with daily resolution. Zonal wave number 7 was used but, consistent with Chang and $\mathrm{Yu}$, the results were not very different when we used wave numbers 6 or 8 . Once $A$ is known, one-point time-lagged correlation maps of $|A|$ can be made and the zonal and meridional packet propagations calculated by tracking the movement of the centres of the correlation. Figure 6 shows the highpass-filtered $v^{\prime}$ and the $|A|$ calculated from it for two 6 day periods, one during the El Niño winter of 1997/98 and one during the La Niña winter of $1998 / 99$. The waves are obvious in the $v^{\prime}$ field and the envelope function $|A|$ tracks the paths of wave energy in both the latitudinal and longitudinal directions. As expected from downstream development, $|A|$ propagates eastward faster than the individual features of $v^{\prime}$. The years in Figure 6 are representative in showing the more southward wave energy path during an El Niño winter.

The direction and speed and amplitude, $|A|$, of wavepacket propagation averaged over all El Niño and La Niña winters is shown in Figure 7. During El Niño 
NCEP Dec 01 - Feb 28 Daily Corr V(300 mb) and V(300 mb, 30N, 180E)
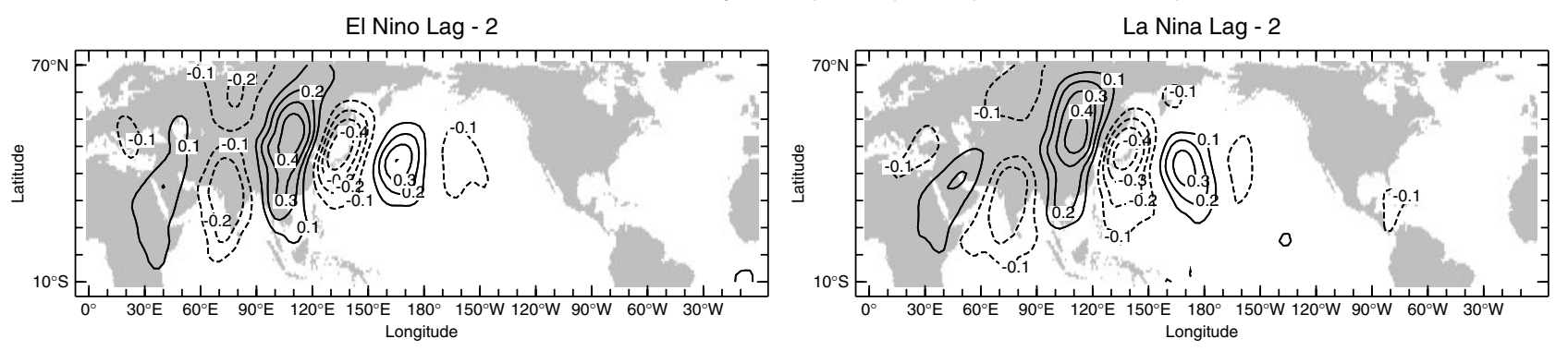

El Nino Lag - 1
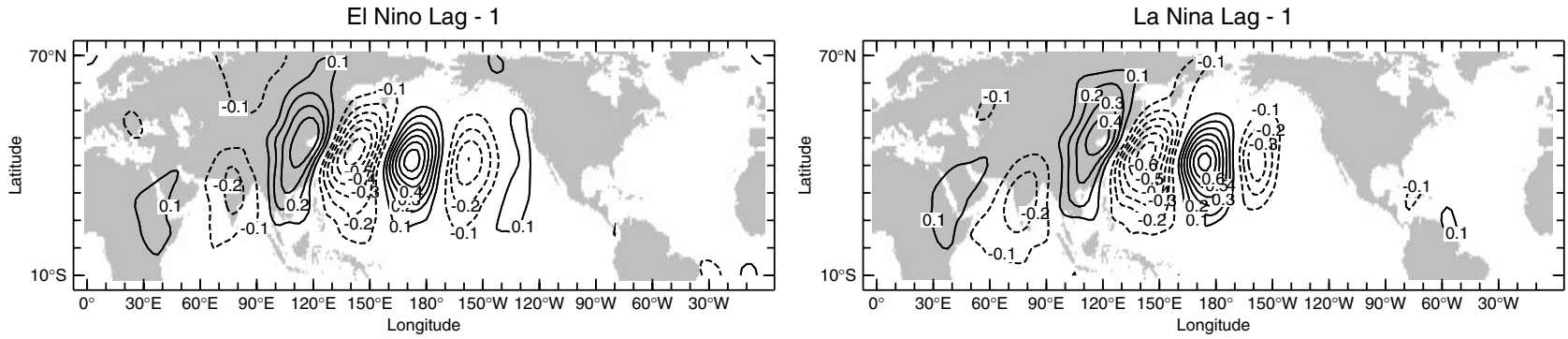

El Nino Lag 0
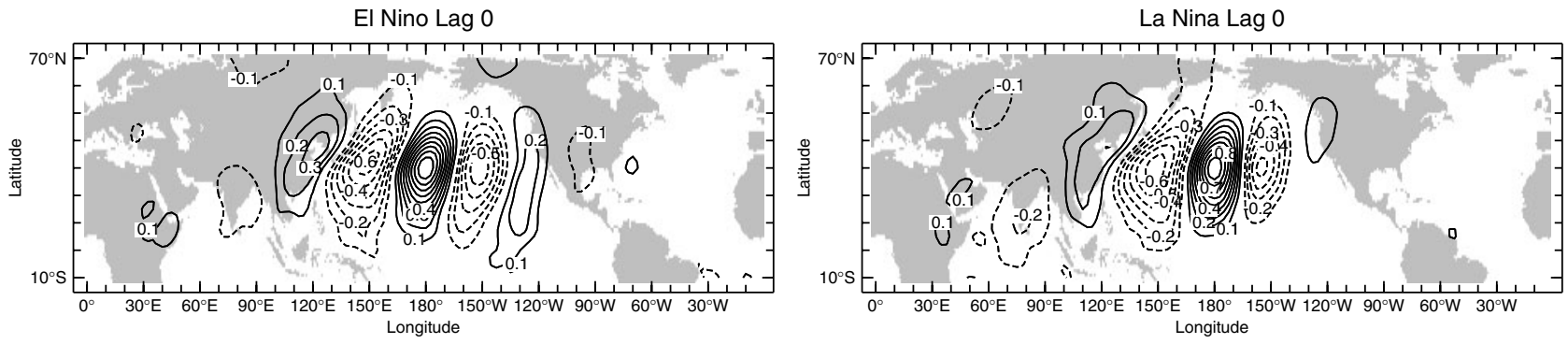

El Nino Lag 1
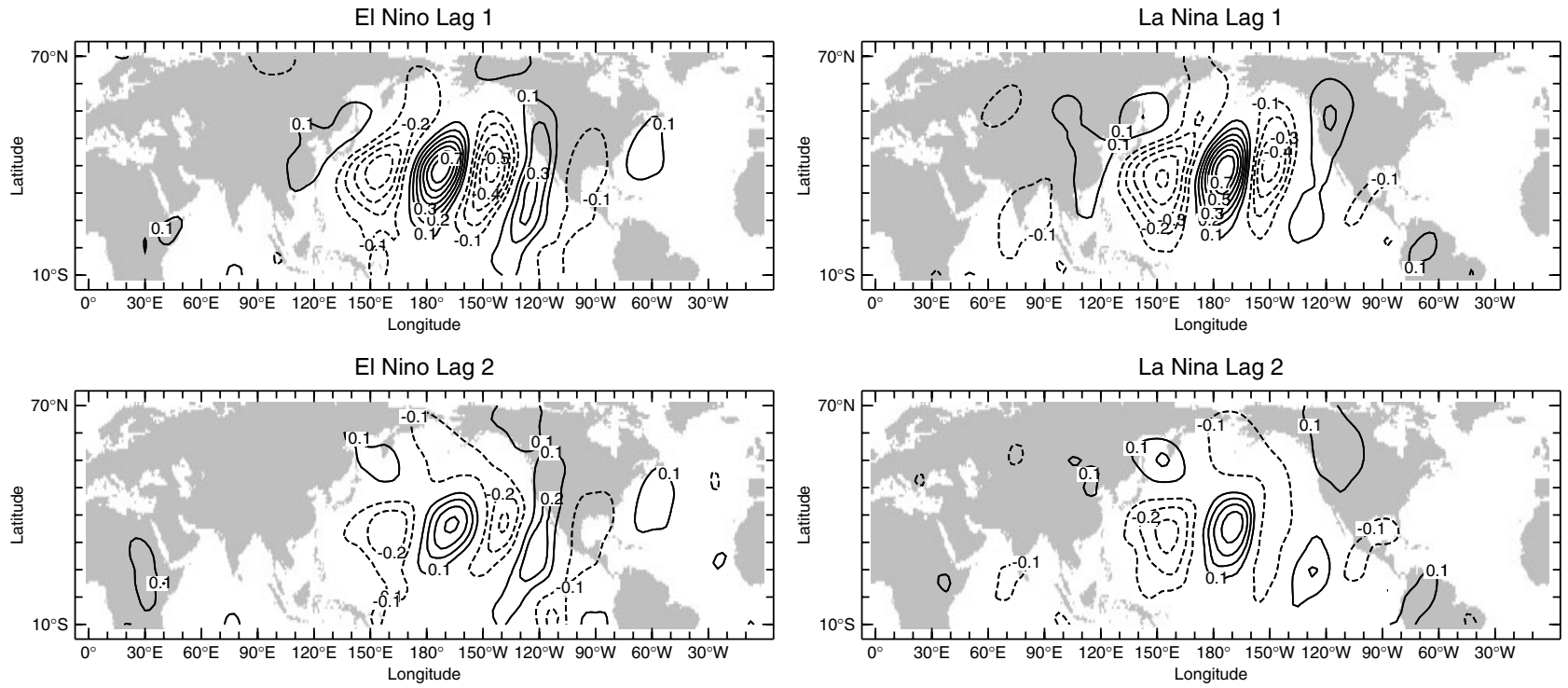

Figure 4. Maps of the correlation between NCEP reanalysis $v^{\prime}$ at $300 \mathrm{mb}$ and $30^{\circ} \mathrm{N}$ and $180^{\circ} \mathrm{E}$ and $v^{\prime}$ everywhere else for lags from -2 to +2 days for El Niño winters (left column) and La Niña winters (right column).

winters, the wave-packet propagation shows a clear eastward propagation of wave energy in a continuous path from Asia across the Pacific and into southern North America, linking with the Atlantic storm track. In contrast, during La Niña winters the wave-packet propagation adopts a more northern track across the Pacific towards the Pacific northwest and then across northern North America to the north Atlantic Ocean. The La Niña winters also show a more prominent leak of wave energy from the midlatitude storm track into the troposphere above the equatorial east Pacific Ocean. These changes in wave-packet propagation are very consistent with the analysis of wave coherence and of phase propagation and clearly indicate differing characteristics of the North Pacific storm track and transient eddy propagation during different phases of ENSO: a more coherent zonal track for El Niño and, for La Niña, a stronger northern track plus a stronger leak from the central Pacific into the Tropics. This change in energy propagation is clearly seen in the plot of the El Niño minus La Niña wave-packet propagation difference (Figure 7, bottom). The southward shift of wave packets is also mirrored in the amplitude anomalies (contours in Figure 7). 

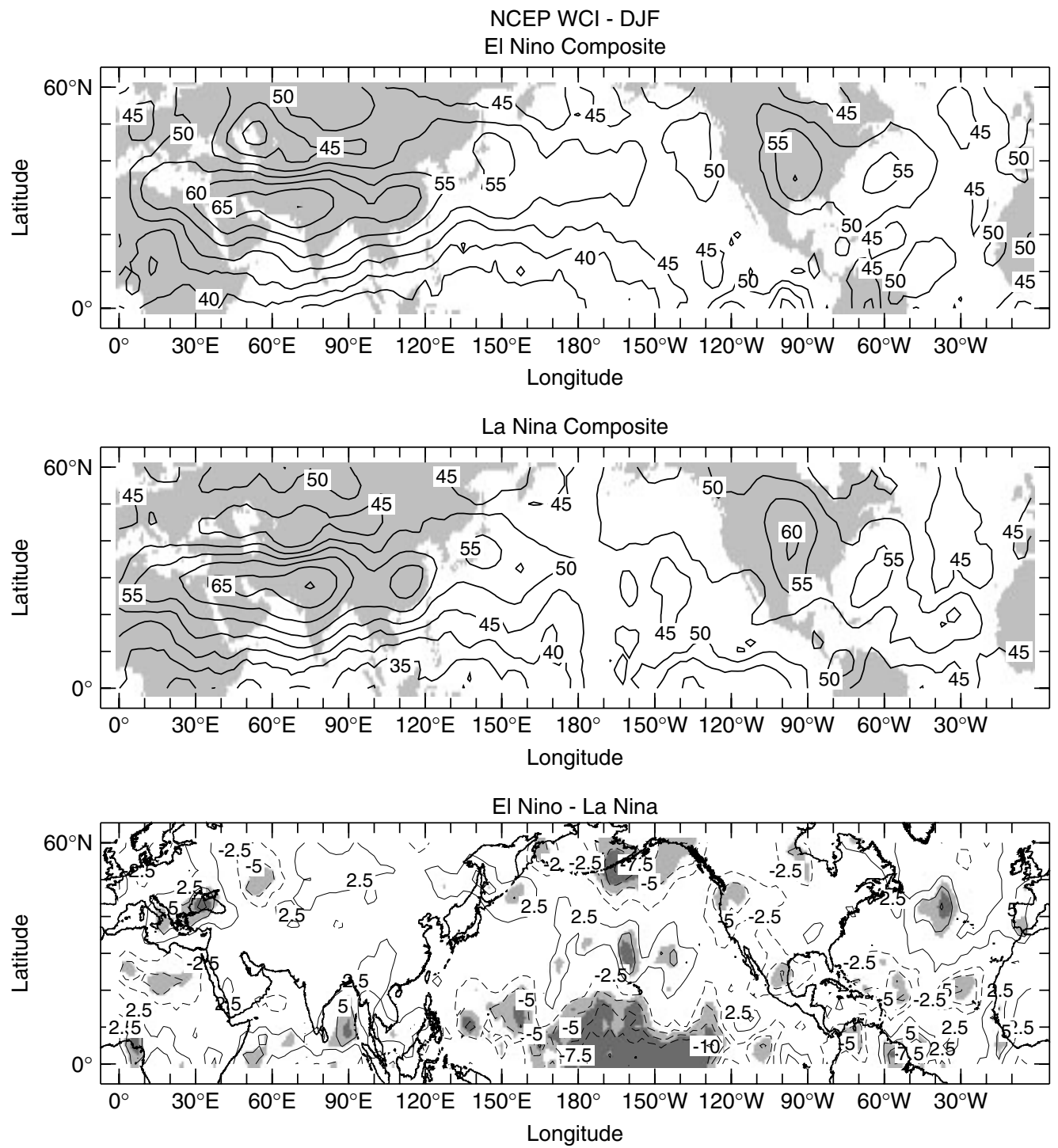

Figure 5. The wave coherence index (WCI) at $300 \mathrm{mb}$ evaluated from the correlation maps of $v^{\prime}$ from NCEP data for El Niño winters (top), La Niña winters (middle) and the difference (bottom). The WCI has been multiplied by 100 for plotting purposes. See the text for more details on the WCI. Shading for significance is as in Figure 1.

\section{ENSO-related changes in transient eddy propagation in idealized SST-forced GCM experiments}

The above diagnostic work describes 'ENSO-related' changes in transient eddy propagation. Even if we accept ENSO as the ultimate cause, it remains to be shown whether the tropical SSTs alone are responsible or whether midlatitude air-sea interaction in the storm-track region or even further poleward is also involved. To determine this, we turn to models in which the ocean influence on the atmospheric circulation can be carefully controlled.

Two 100 member ensembles of 100 day integrations were forced by canonical El Niño and La Niña winter SSTs in the tropical Pacific Ocean, with climatological SSTs imposed everywhere else in all cases. We focus on the near-statistical steady-state solution achieved during days $61-100$ of the model simulations. Since the model runs begin on December 1 , this is primarily a February response.

Figure 8 shows modelled $\overline{u^{\prime} v^{\prime}}$ and $\overline{v^{\prime 2}}$, computed using the same high-pass filter that was applied to the reanalysis. The patterns and magnitudes are clearly similar to those observed (Figures 2 and 3).
The wave coherence index (WCI) is computed from days 61-100 of each of the ensemble members, beginning with the same one-point correlation analysis as was used for the observations. As for the observations, we also computed wave-packet propagation directions, speeds and amplitudes from the $v^{\prime}$ data. Results are plotted in Figure 9. The model WCIs for cases of El Niño and La Niña forcing are quite similar to those observed (not shown) and the difference clearly shows the zonally oriented wave propagation route for El Niño and the relatively north-south split route for La Niña. (Note that the values in the observational plot were multiplied by 100 for plotting purposes.) These model results are backed up by the model wave-packet propagation, which again shows the more zonal and southward propagation route of wave energy over the east Pacific and North America for El Niño, together with increased wave-packet amplitude in the same region (contours in Figure 9).

The similarity of the modelled and observed variability of transient eddy propagation in the Pacific-North America sector makes an important point: since only the tropical Pacific SSTs are specified, the modelled, and by implication the observed, changes in eddy propagation are forced from 

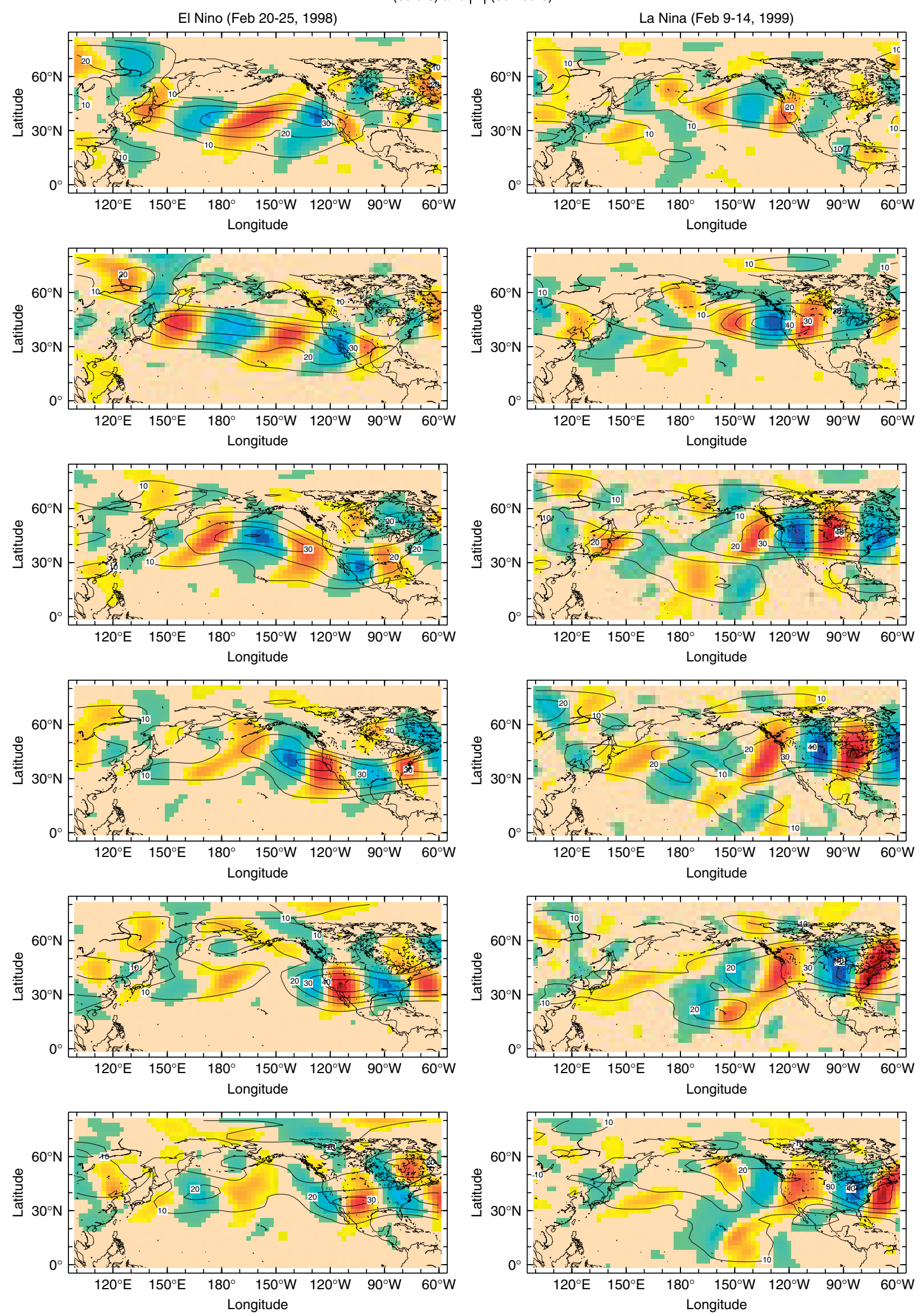

Figure 6. The high-pass-filtered meridional velocity $v^{\prime}$ (colour) and the envelope function $|A|$ (contours) computed from $v^{\prime}$ for two six-day periods during the El Niño winter of 1997/98 (left) and the La Niña winter of 1998/99 (right). Each row represents a different day in the sequence, with time increasing from top to bottom. Units are $\mathrm{m} \mathrm{s}^{-1}$ with the colour scale for $v^{\prime}$ ranging from -50 to $+50 \mathrm{~m} \mathrm{~s}^{-1}$. 

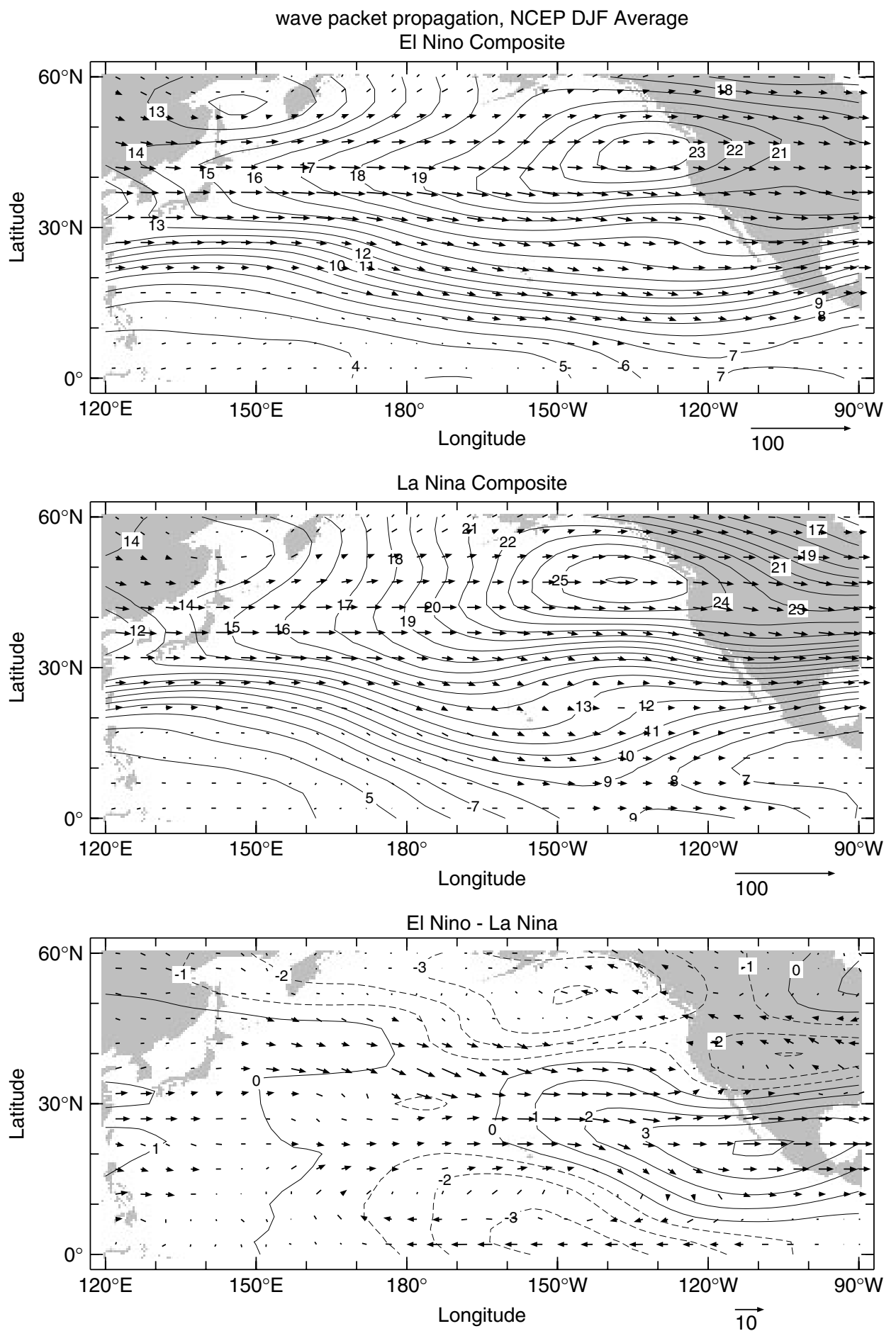

Figure 7. The observed direction and speed (vectors) of propagation of wave packets for El Niño winters (top), La Niña winters (middle) and the difference (bottom). Contours show the amplitude of the envelope function $|A|$. Results are computed from lag correlations of the envelope function $A$ of high-pass meridional velocity at $300 \mathrm{mb}$. Units are $\mathrm{m} \mathrm{s}^{-1}$.

the tropical Pacific SST anomalies and do not require the involvement of air-sea interaction outside the tropical Pacific.

\section{Diagnosis of the transient eddy response to ENSO- related mean-flow variations using an idealized GCM}

The conclusion above means that the adjustment of the mean and transient atmospheric circulation to ENSO SST anomalies should be understandable in terms of (1) SST forcing of a mean-flow anomaly, (2) a transient eddy response to that and (3) a subsequent transient eddy forcing of the mean flow. To make the first step, we use an idealized GCM, the time-dependent primitive equation model with R30 horizontal resolution and 14 sigma-coordinate vertical layers linearized about a prescribed three-dimensional basic state described in Ting and $\mathrm{Yu}$ (1998). In this study, we use a weaker biharmonic diffusion of $1 \times 10^{16} \mathrm{~m}^{4} \mathrm{~s}^{-1}$ and a Rayleigh friction time-scale of 35 days in the free atmosphere, gradually increasing to 1 day at the lowest model layer in order to allow transients and baroclinic instability. The model was linearized about the La Niña and El Niño basic 

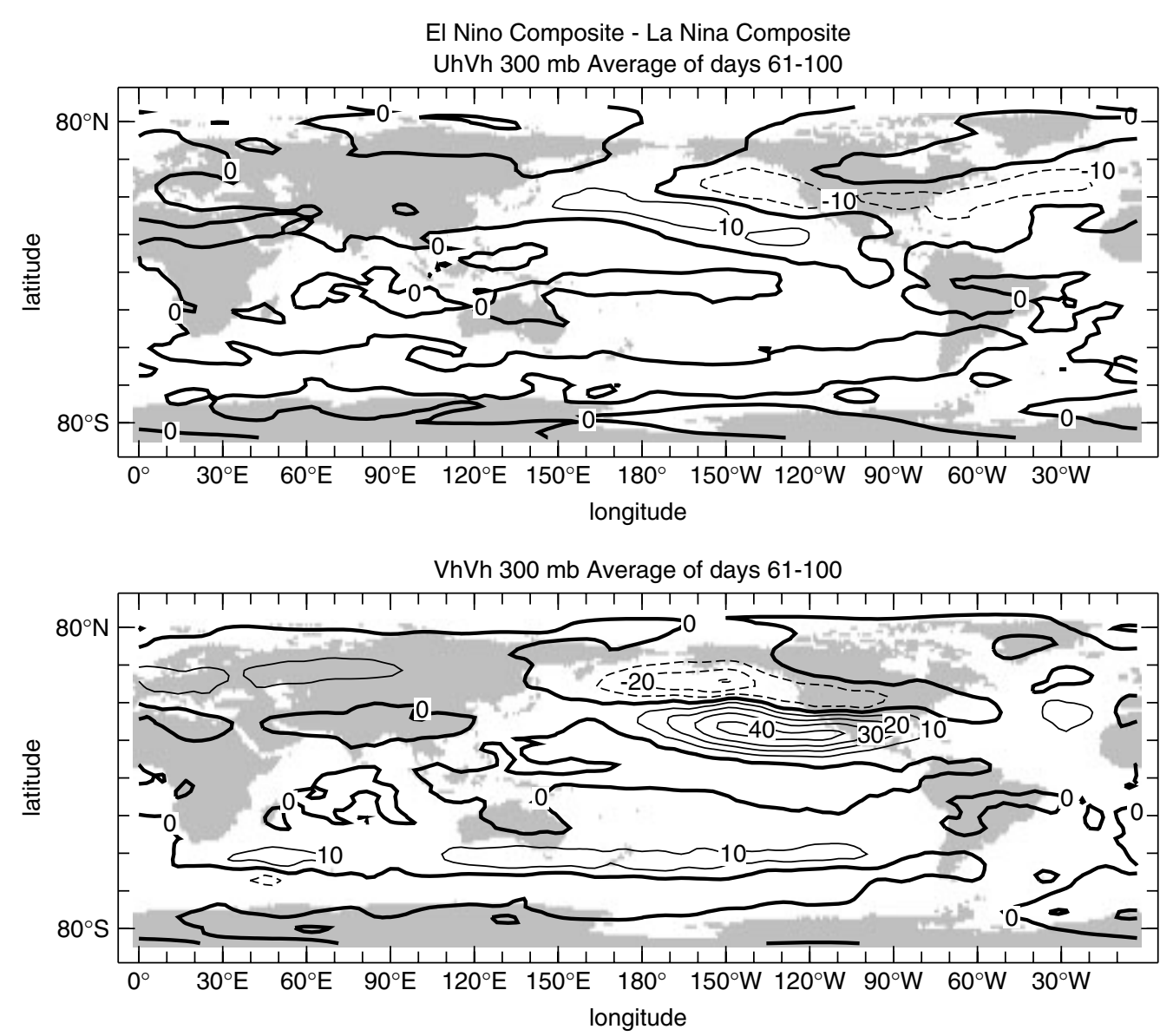

Figure 8. $\overline{u^{\prime} v^{\prime}}$ (top) and $\overline{v^{\prime 2}}$ (bottom) for days 61-100 of the 100 member ensemble mean of the 100 day long SST-anomaly-forced GCM integrations for the case of an El Niño forcing minus a La Niña forcing. Units are $\mathrm{m}^{2} \mathrm{~s}^{-2}$.

states deduced from the NCEP-NCAR reanalyses through compositing, as described for the observational analysis. Only dry dynamics are included.

Our goal is to examine the impact of the imposed basic states on the propagation of transient eddies. We force the model with heating perturbations over the Asian region only $\left(60-140^{\circ} \mathrm{E}, 10-40^{\circ} \mathrm{N}\right)$ that are random in time and space. The vertically coherent heating perturbations have a mid-tropospheric peak and tail off to zero at the surface and the top of the model. The spatially uncorrelated heating field is then smoothed with a 1-2-1 filter applied twice in each direction to impose some horizontal correlation. This forcing excites a succession of baroclinic, transient eddies that propagate eastward across the Pacific Ocean. Branstator (1995) and Zhang and Held (1999) used a similar approach, but with global forcing, to generate a storm track in a linearized GCM, and the latter article showed that it reproduced the observed storm-track anomaly for one El Niño winter.

Here we use Ting and Yu's (1998) nonlinear version of the model in which the wave-wave interaction terms are retained even though the model contains a specified basic state. Nonlinear processes in the model effectively control eddy growth (even though, since the modelled storm track is weaker than observed, the wave-wave interaction terms are weaker than observed). With the low damping used, even with random forcing over the Asia region alone the model creates a near-circumglobal storm track. However, the amplitude of the modelled storm track is sensitive to the values of forcing and damping imposed and consequently we do not expect the storm-track amplitudes to match those in observations or in the GCM. The model should also not be too closely compared with globally forced models such as that of Zhang and Held (1999). Our purpose in forcing the model over the Asian region alone is to isolate as much as possible the process of refraction as storms generated over Asia propagate eastward across the Pacific towards North America. Hence we restrict ourselves below to a comparison of the spatial patterns, rather than amplitudes, of the stormtrack anomalies in the Pacific North America sector. Results are shown for the average over a 10 member ensemble.

\subsection{Results from the nonlinear storm-track model with observed basic states}

For the nonlinear storm-track model, with imposed basic states taken from the NCEP reanalysis, the high-pass-filtered $\overline{u^{\prime} v^{\prime}}$ and $\overline{v^{\prime 2}}$ at $300 \mathrm{mb}$ for the El Niño and La Niña basic states are shown in Figures 11 and 12. A Pacific storm track is generated with, for $\overline{v^{\prime 2}}$, a maximum over the central and eastern Pacific, which extends across the Atlantic (where it is too far south) before weakening over the European and Asian continents. Since the model is only forced over Asia, greater similarity with the observed storm track is not necessarily expected. The modelled storm tracks are distinctly different for the two basic states. Figure 10 shows snapshots of the high-pass-filtered $v^{\prime}$ at 5 day intervals towards the end of two of the simulations. Amidst considerable day-today variability, for the El Niño basic state eddies tend to 

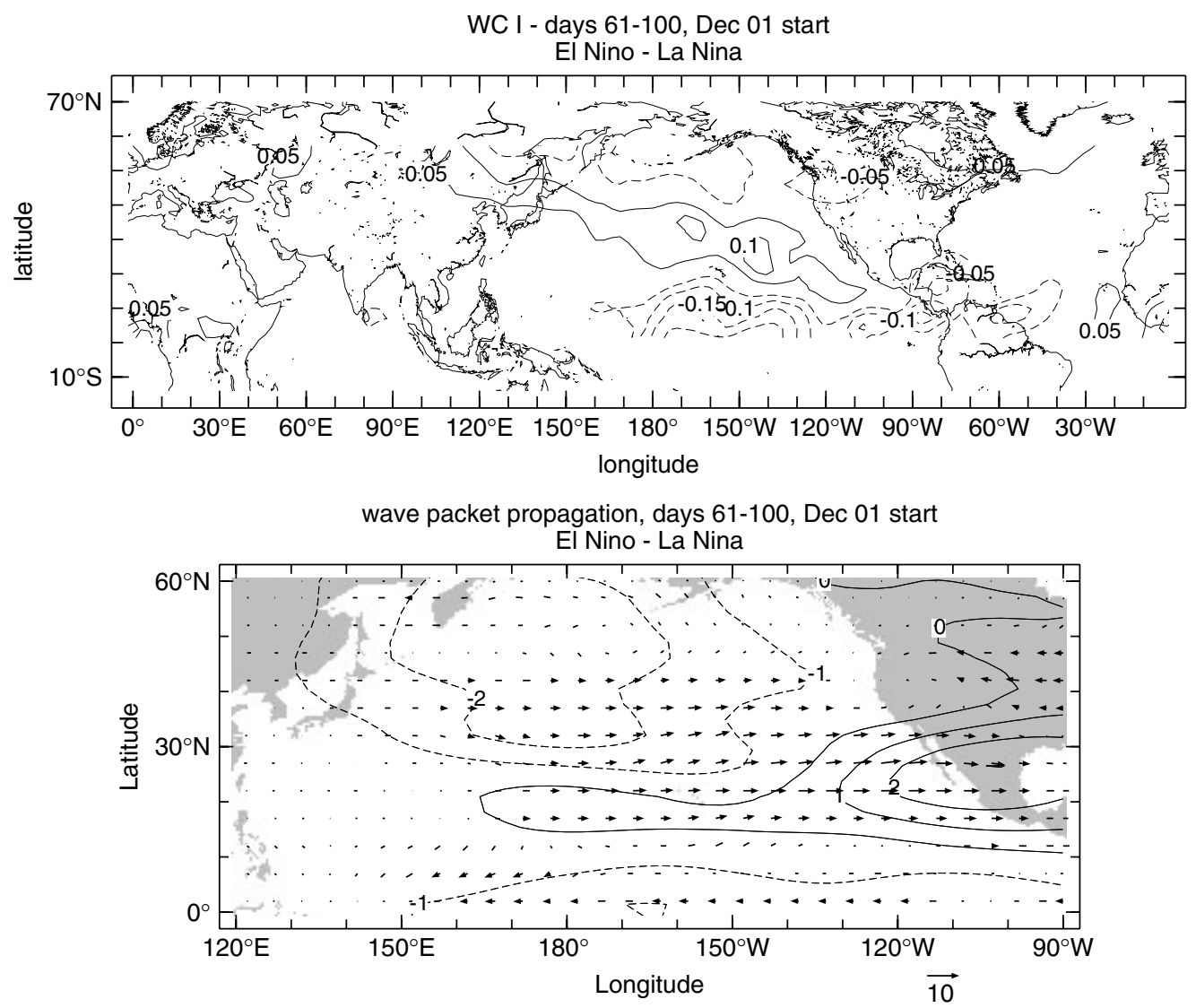

Figure 9. The difference in wave coherence index (top) and wave-packet propagation direction (vectors) and amplitude (contours) from days 61-100 of the SST-anomaly-forced model integrations for the case of El Niño forcing minus La Niña forcing (top). Units are $\mathrm{m} \mathrm{s}{ }^{-1}$.

propagate strongly into southwestern North America while for the La Niña basic state the main path of eddy propagation tends towards the Pacific Northwest and Canada, with an additional leakage of wave energy into the tropical east Pacific. The resemblance to observations is clear.

The eddy covariances, $\overline{u^{\prime} v^{\prime}}$ and $\overline{v^{\prime 2}}$, averaged over the length of the simulations and the ensemble are shown in Figures 11 and 12 for the two basic states and their difference. The eddy momentum flux difference shows the strong, more zonal, storm track for the El Niño basic state with positive perturbations from the central Pacific, across southern North America and across the subtropical Atlantic Ocean with negative perturbations to the north. This is much like the observed pattern of ENSO-related $\overline{u^{\prime} v^{\prime}}$ shown in Figure 2. Similarly the pattern of $\overline{v^{\prime 2}}$ shows the southwardshifted stormtrack for the El Niño basic states, similar to the observed ENSO-related anomalies shown in Figure 3.

The patterns of changes in the eddy statistics over the Pacific-North America sector were qualitatively similar in a linear version of the model. This suggests that the spatial pattern is controlled by linear processes but that nonlinear processes are important to control eddy growth and improve the realism of the storm track away from the region of forcing. The reasonably realistic results of the storm-track models indicate that the ENSO-related changes in the storm track in the Pacific-North America sector can be at least partially understood in terms of the impact that changes in the mean flow have on the propagation and growth of transient eddies governed by linear, dry, dynamics.

Orlanski (2005) suggested that the more southwardand eastward-extended storm track in El Niño winters is partially caused by regeneration of transient eddies in the central Pacific as they encounter the enhanced baroclinicity caused by the tropical tropospheric warming associated with the warm equatorial SST anomaly and enhanced deep convective heating over the central and eastern tropical Pacific Ocean. This mechanism is potentially contained in the linear and nonlinear models, since the specified flow fields contain the changes in baroclinicity. Thus the changes in eddy paths in the models can arise from either changes in wave refraction and/or changes in eddy regeneration as the eddies move across the Pacific Ocean.

To check the relative importance of refraction and eddy regeneration we computed the baroclinic energy conversion as given by $(\bar{\alpha} / \bar{\theta})(\partial \bar{\theta} / \partial p)^{-1}\left(\overline{\mathbf{v}^{\prime} \theta^{\prime}} \cdot \nabla \bar{\theta}\right)$ (Chang et al., 2002), where $\bar{\alpha}$ is the inverse of the mean density, $\theta$ is potential temperature, primes denote high-pass-filtered values and bars denote the specified mean-state fields. The energy conversion for NCEP climatology, El Niño minus La Niña NCEP winters and the El Niño minus La Niña difference from the nonlinear storm-track model, all integrated from $850-300 \mathrm{mb}$, are shown in Figure 13. The climatological patterns have maximum values over the western and central North Pacific and Atlantic Oceans, much as in Chang et al. (2002). The observed difference shows enhanced energy conversion east of Japan during El Niño winters. This seems to be a response to enhanced horizontal temperature gradients there associated with warming over regions of Asia to the southwest and cooling over the ocean to the northwest, a pattern driven by the stationary wave response to tropical SST anomalies. This increased energy conversion east of Japan is reproduced in the storm-track 
Vh at $250 \mathrm{mb}$
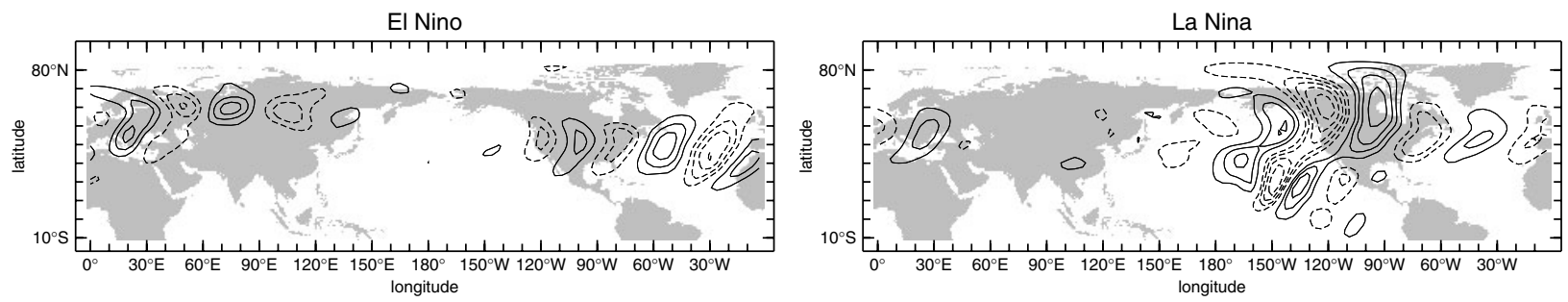

day 70

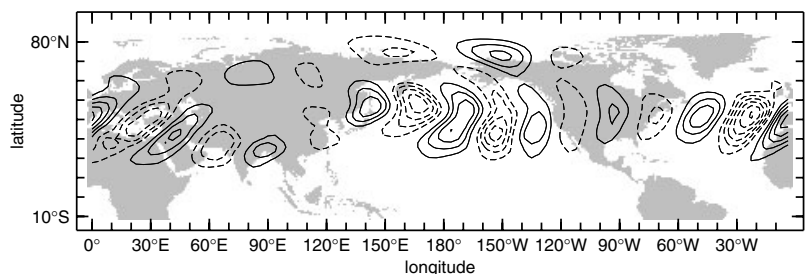

day 70

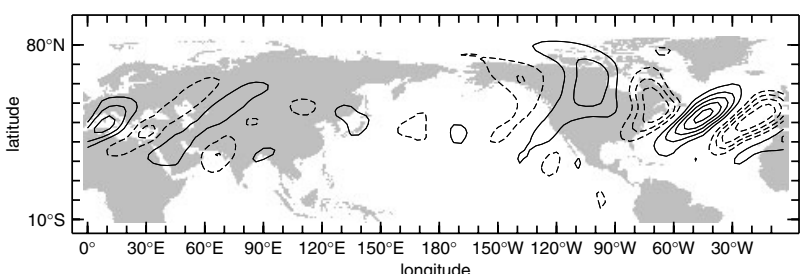

day 75
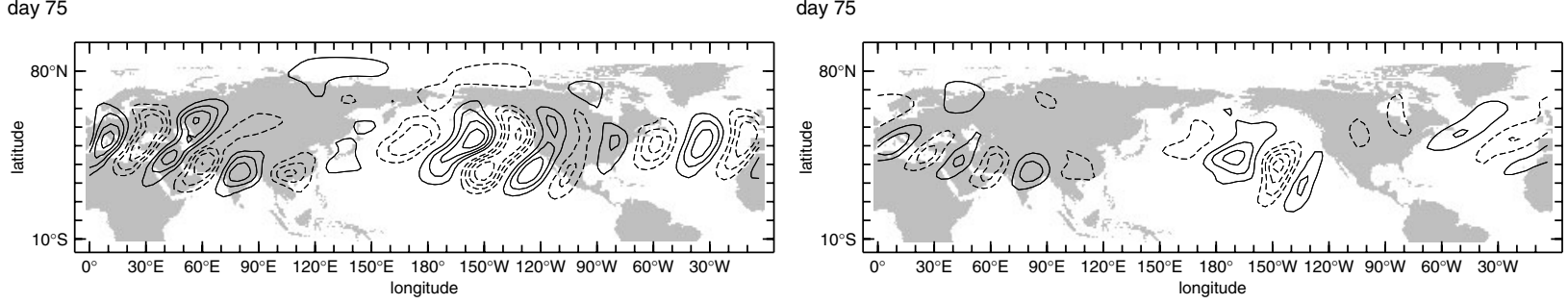

day 80

day 80
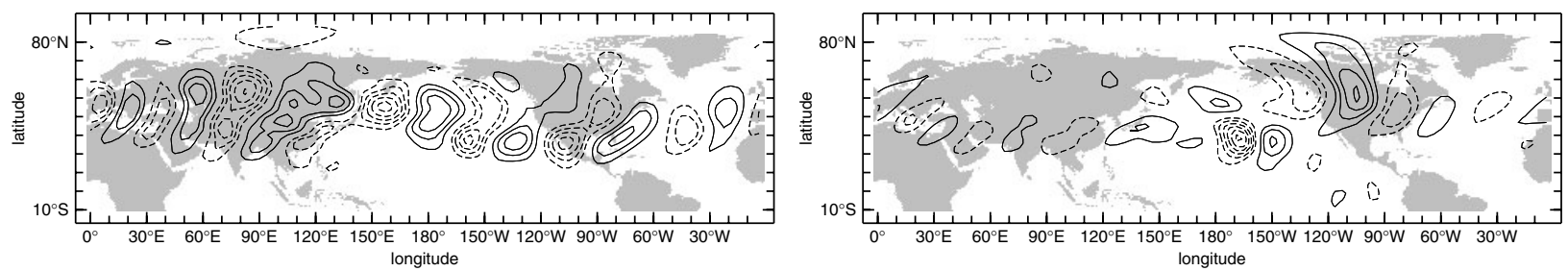

day 85

day 85
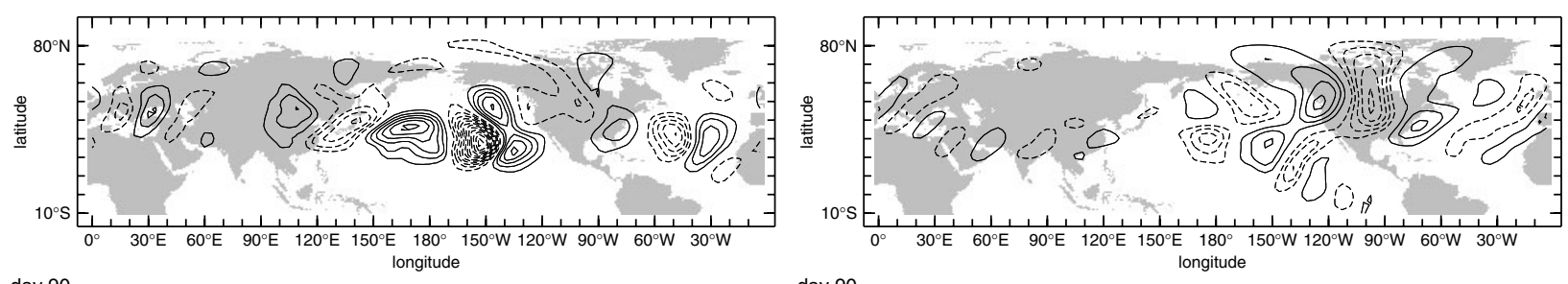

day 90
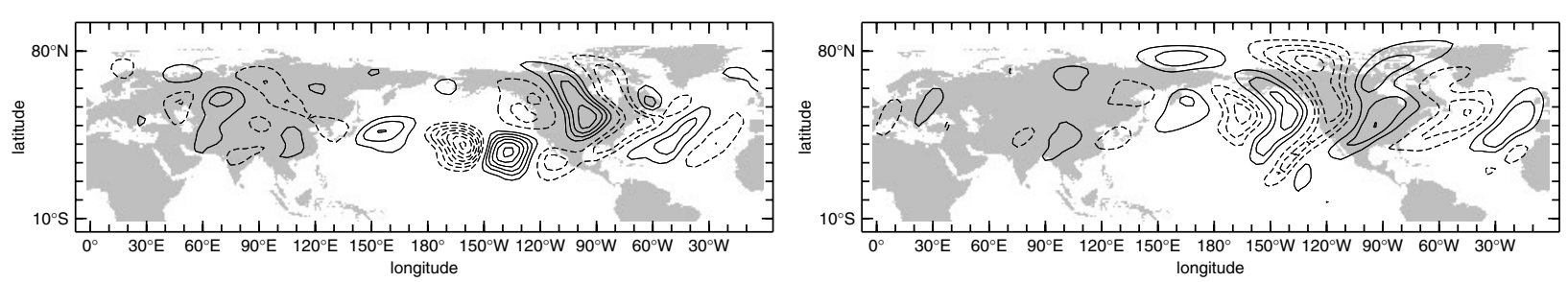

day 95

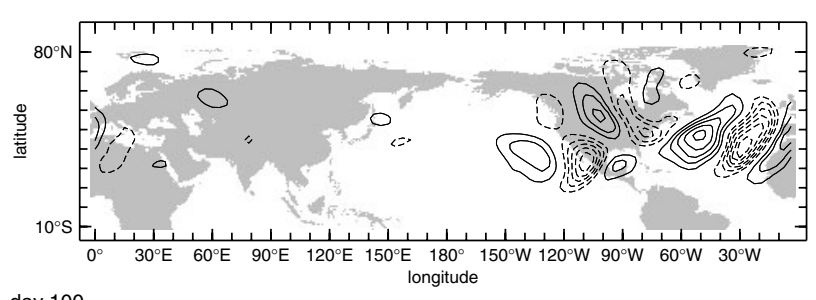

day 95

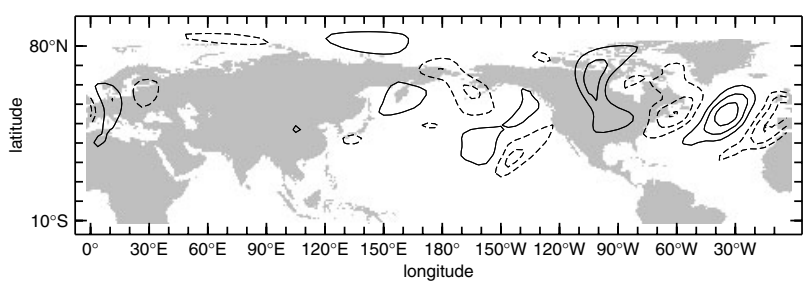

day 100

Figure 10. Snapshots of the high-pass-filtered meridional velocity $\left(\mathrm{m} \mathrm{s}^{-1}\right)$ at $250 \mathrm{mb}$ from two simulations with the nonlinear storm-track model with a specified El Niño basic state (left) and La Niña basic state (right) for, from top to bottom, days 70, 75, 80, 85, 90, 95 and 100. The more zonal eddy path for El Niño winters is clear compared with a more split path, with strong propagation into the Pacific Northwest, for La Niña winters. 

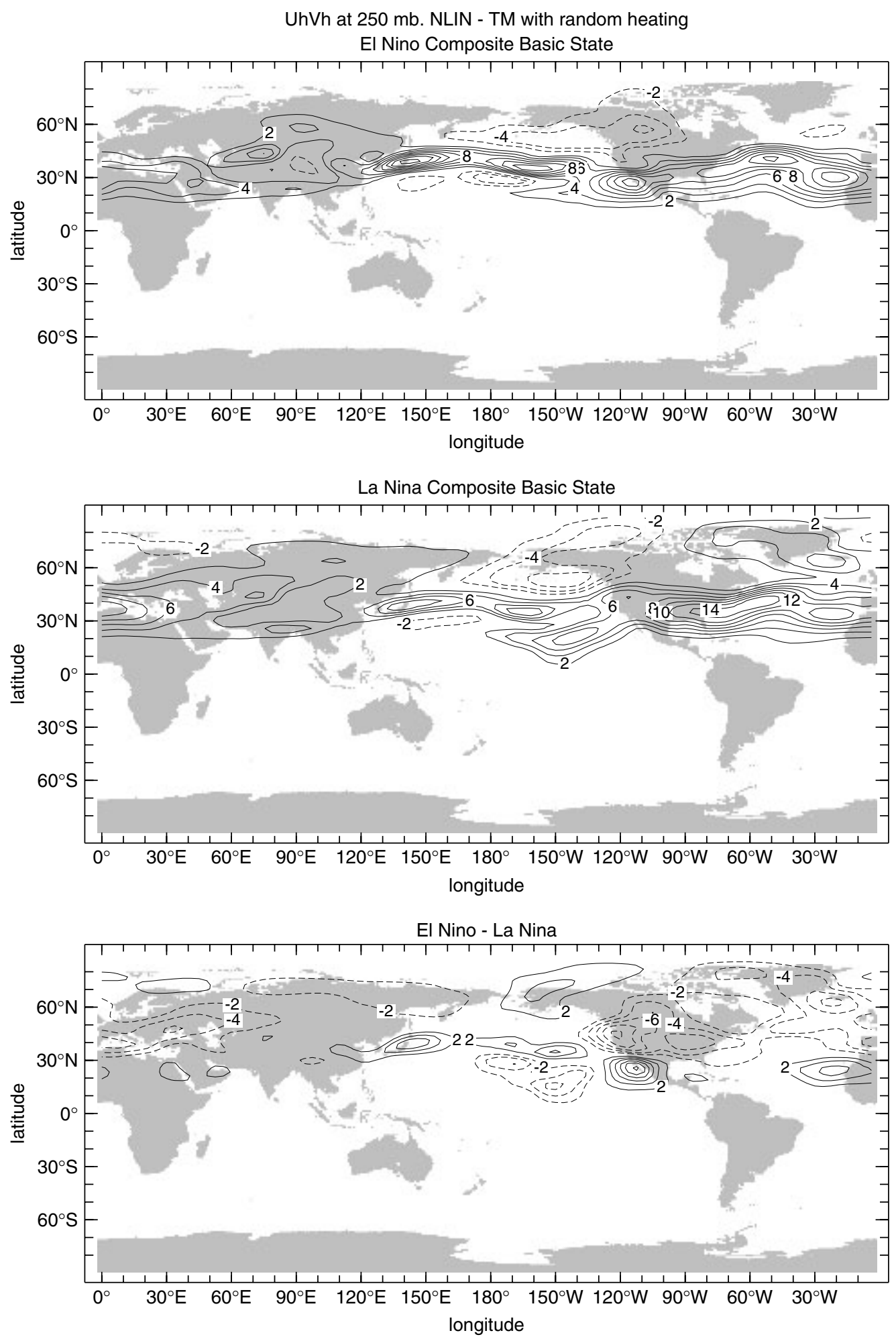

Figure 11. The high-pass-filtered $250 \mathrm{mb}$ transient eddy momentum flux, $\overline{u^{\prime} v^{\prime}}$, from the nonlinear storm-track model with a specified El Niño basic state (top), a La Niña basic state (middle) and the difference (bottom). Units are in $\mathrm{m}^{2} \mathrm{~s}^{-2}$.

model (albeit with a weaker amplitude as expected given the weaker storm track). Despite the observed and modelled storm track being more equatorward in El Niño winters, there is no evidence of enhanced energy conversion on the poleward flanks of the tropical warming in the eastern central Pacific. Instead, away from the region east of Japan the changes in energy conversion appear to follow the change in storm-track path, i.e. to track $\overline{\mathbf{v}^{\prime} \theta^{\prime}}$ rather than tracking changes in the mean state. This suggests that the changes in the eddy propagation paths are caused by wave refraction and that where the eddies go they extract energy.

5.2. Results from the nonlinear storm-track model with basic states imposed from the transient adjustment simulations

The problem with a calculation as just performed with the storm-track model is that the basic states that were imposed already have the impacts of eddies within them. 

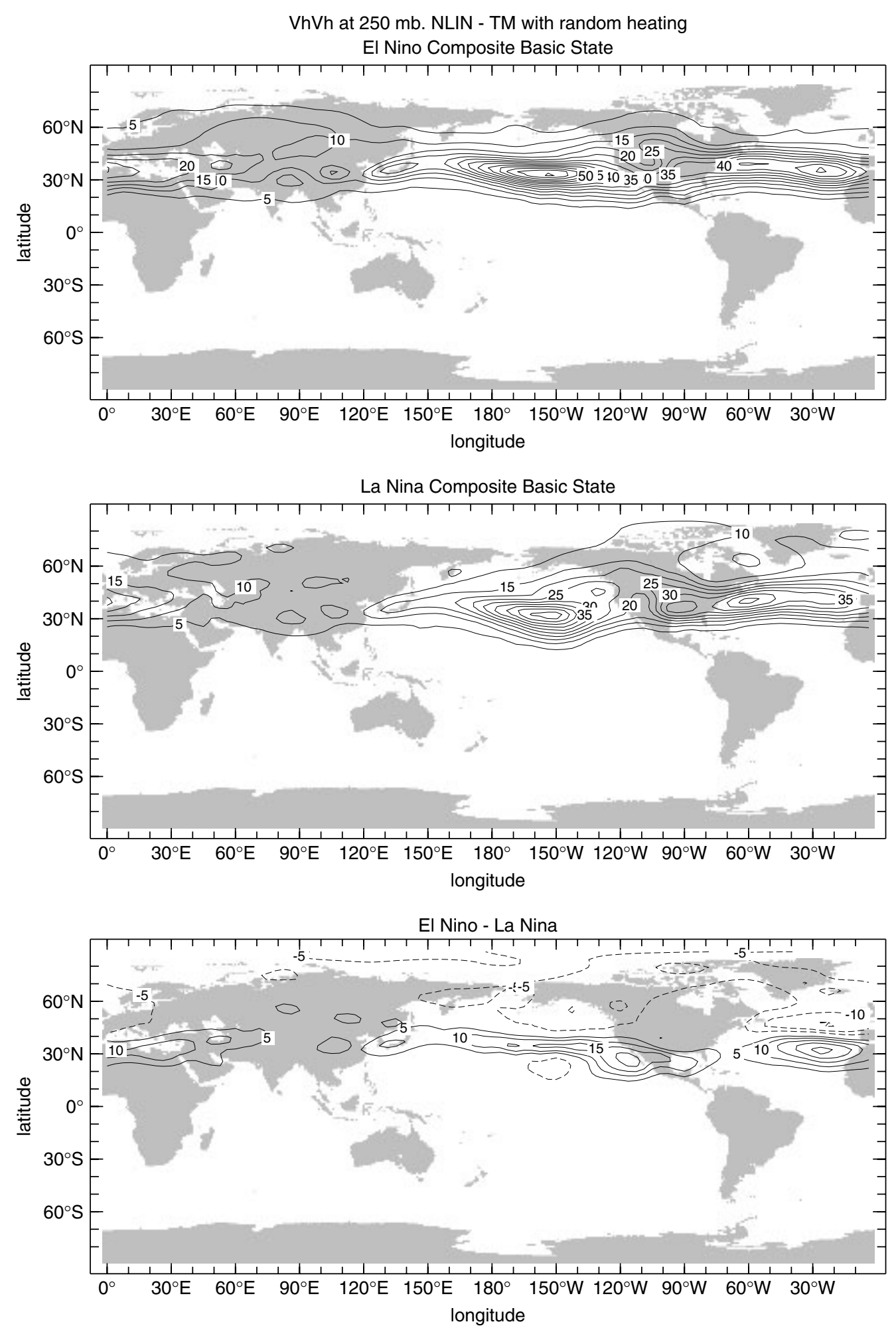

Figure 12. As for Figure 11 but for the high-pass-filtered variance of the $250 \mathrm{mb}$ meridional velocity, $\overline{v^{\prime 2}}$, from the nonlinear storm-track model. Units are in $\mathrm{m}^{2} \mathrm{~s}^{-2}$.

To look more at the issue of causality, we return to the ensembles of GCM simulations of the 100 day adjustment of the circulation to an instantaneous insertion of ENSO SST anomalies. Early in these simulations, the mean-flow anomalies are primarily driven by the anomalies in tropical heating and it is only after a week or two that the transient eddies begin to respond and, subsequently after that, to impact the mean flow (Harnik et al., 2010). By running the storm-track model with basic states from different times within the 100 day GCM simulations, we can examine how transient eddy propagation and the eddy fluxes evolve after the initial turn-on of an ENSO SST anomaly. In order to see more clearly the signal of the changes in the storm track between the different time periods, including the early ones when the mean-flow anomaly is relatively small, the ensemble size was increased to 200 .

Figure 14 shows the $\overline{u^{\prime} v^{\prime}}$ and $\overline{v^{\prime 2}}$ anomalies from the storm-track model using basic states from the El Niño and 

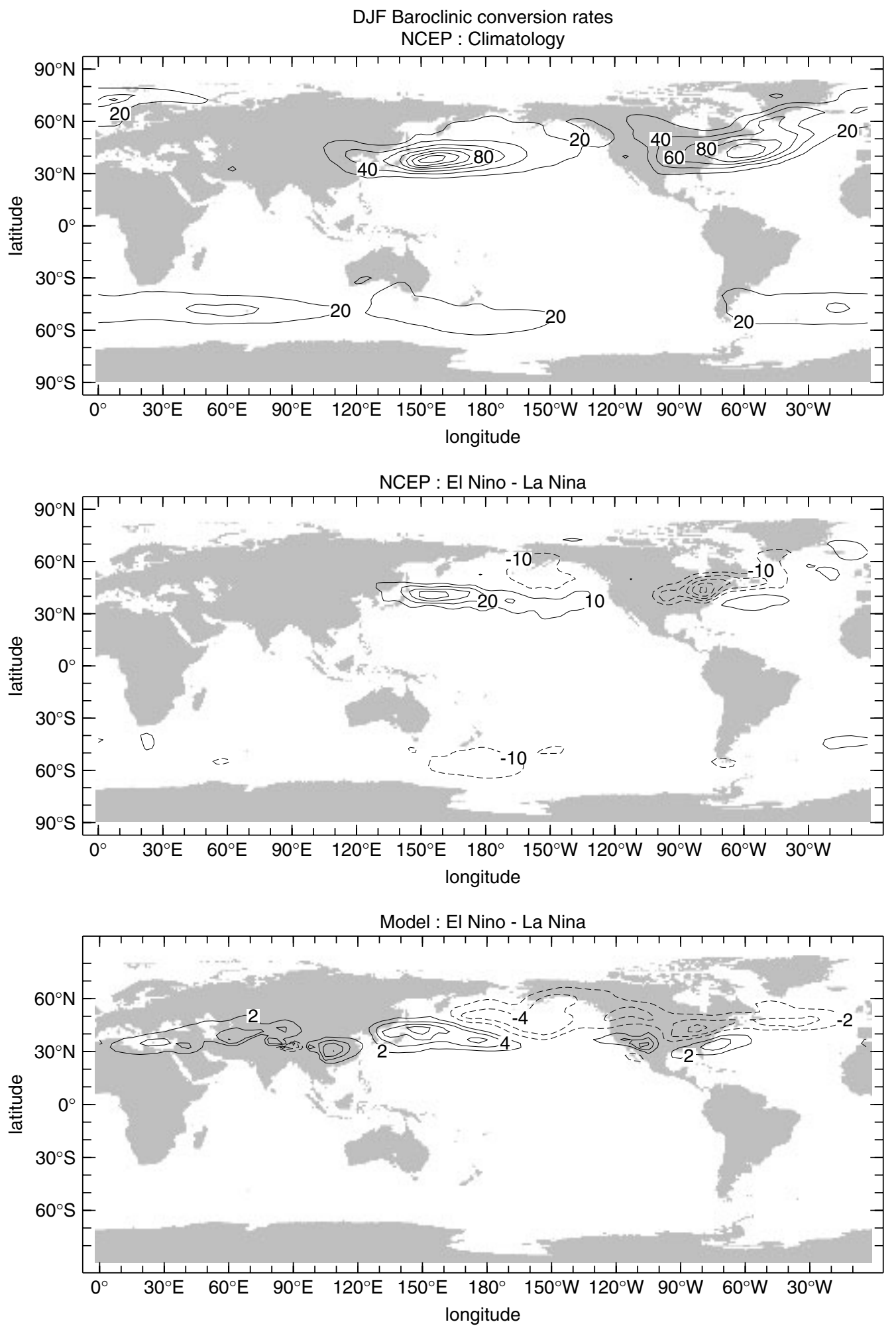

Figure 13. The baroclinic conversion of energy from the specified mean state to the transient eddies for the observed climatology (top) and the observed El Niño minus La Niña difference (middle) and, in the nonlinear storm-track model, for the case with an El Niño basic state minus the case with a La Niña basic state (bottom). Units are $\mathrm{m}^{2} \mathrm{~s}^{-2}$ day $^{-1}$.

La Niña SST-forced GCM simulations taken from days $7-14,15-30,31-60$ and the statistical near-steady state for days 61-100. First, note that the eddy covariances in the storm-track model for the statistical steady state are in reasonable agreement with those derived when imposing the observed basic states. For the day 7-14 basic state, before eddy fluxes have significantly impacted the mean flow, the patterns of anomalous $\overline{u^{\prime} v^{\prime}}$ and $\overline{v^{\prime 2}}$ show positive values south of negative values over the eastern Pacific-North America sector. At this early time the eddies are responding, through refraction, to the directly tropical-heating-forced mean-flow anomalies. These dipole patterns evolve and strengthen as the basic state field is updated. The time-scale for adjustment of stationary waves to a tropical forcing is shorter and of the order of tens of days (Hoskins and Karoly, 1981). Consequently, the strengthening over the 100 days 
NLIN - TM with random heating, 200 runseach $250 \mathrm{mb}$ El Nino - La Ninadi erences

UhVh

day $7-14$ basic state

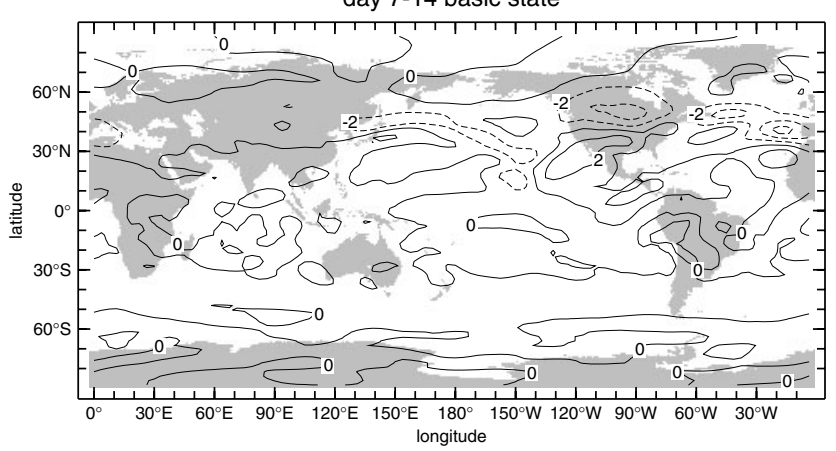

day $15-30$ basic state

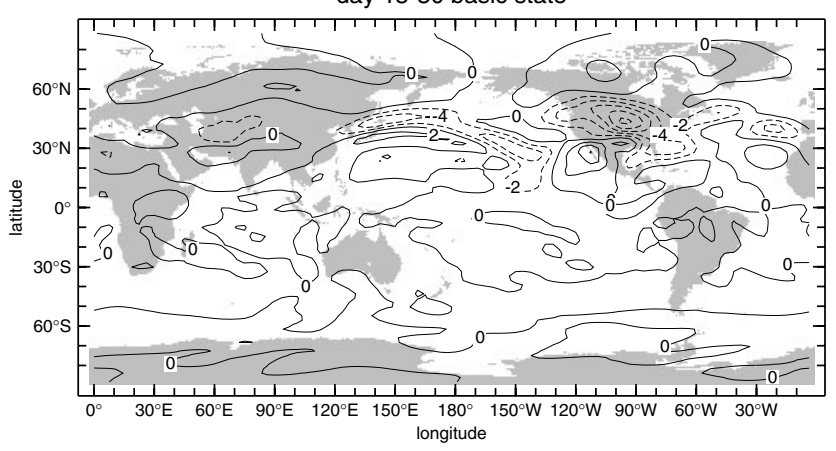

day $31-60$ basic state

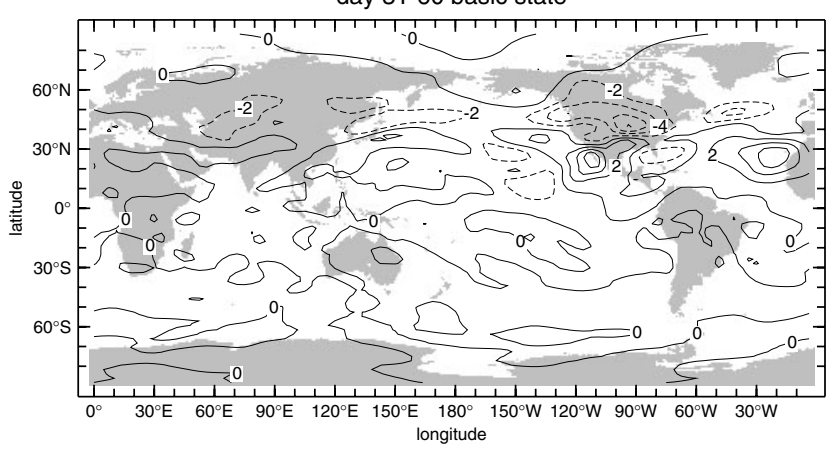

day $61-100$ basic state

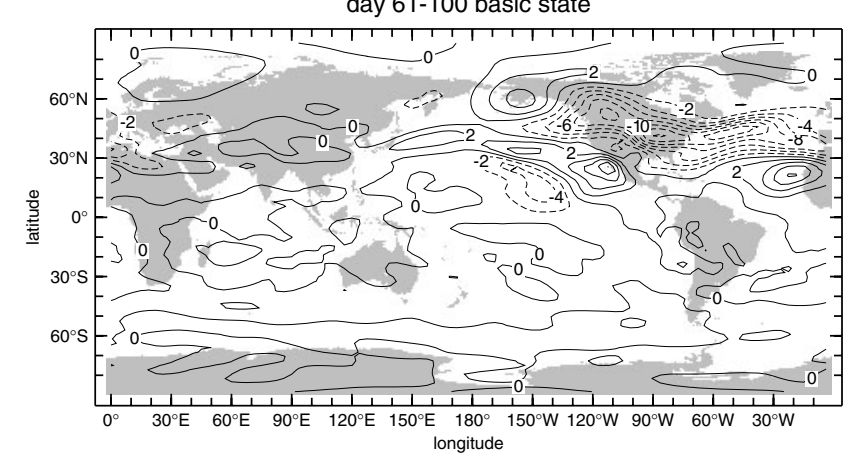

$\mathrm{VhVh}$

day 7-14 basic state

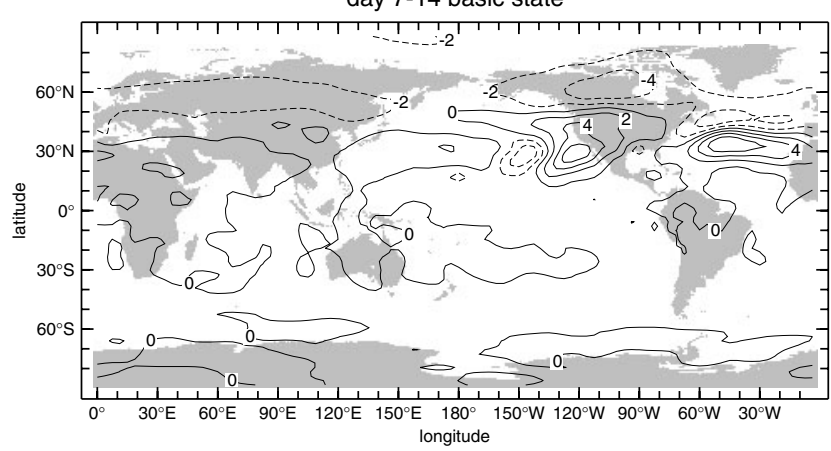

day $15-30$ basic state

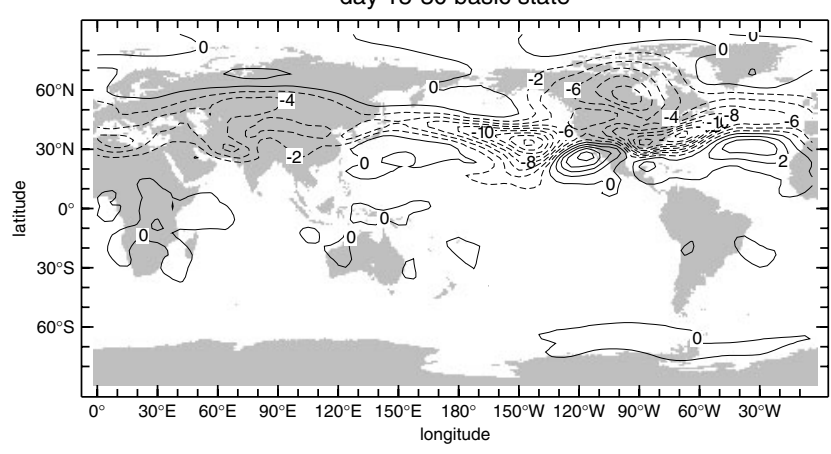

day 31-60 basic state

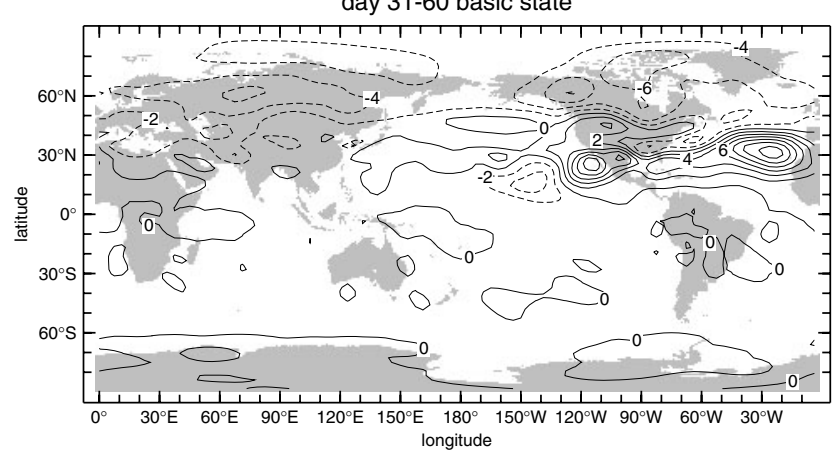

day $61-100$ basic state

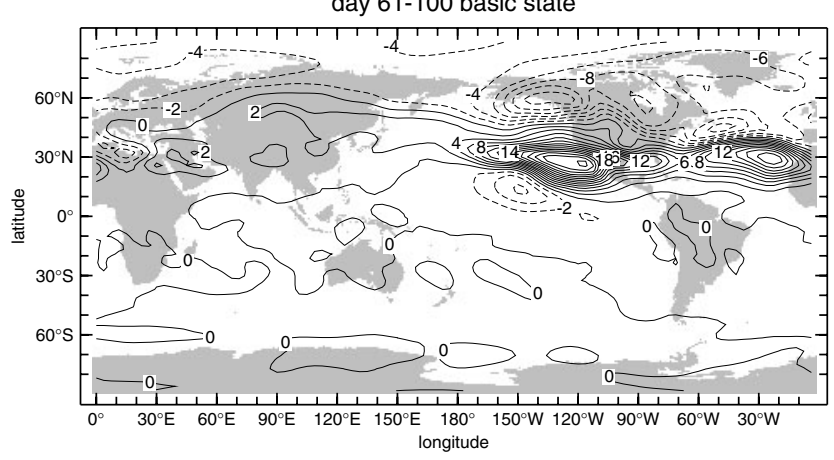

Figure 14. The $\overline{u^{\prime} v^{\prime}}$ (left) and $\overline{v^{\prime 2}}$ (right) anomalies at $250 \mathrm{mb}$ from the nonlinear storm-track model when ensemble mean basic states are specified from days 7-14, days 15-30, days 31-60 and 61-100 of the 100 day GCM simulations with imposed ENSO SST anomalies. Units are $\mathrm{m}^{2} \mathrm{~s}^{-2}$.

of the eddy covariance anomaly patterns in the storm-track model, which is accompanied by a strengthening of the mean-flow anomaly patterns (not shown), is suggestive of a positive eddy-mean-flow feedback. This recalls the idea of Branstator (1995) that on longer than synoptic time-scales it will be those flow anomalies that excite a positive feedback between waves and the mean flow that will persist. However, the eddy response is not simply a positive feedback but also incites an evolution over time of the mean and transient circulation (Harnik et al., 2010).

The refraction argument for changes in paths of transient eddy propagation is outlined in some detail in Seager et al. (2003). Briefly, eddies tend to propagate towards regions of high wave number. This was shown analytically for waves of non-zero frequency propagating in the latitude height domain by Karoly and Hoskins (1982) and from 
numerical calculations in Seager et al. (2003). The eddy wave number is influenced by the mean flow. During El Niños the tropically forced positive zonal mean-flow anomaly, acting alone, would tend to lower the wave number. However the anomalous flow also creates an anomalous positive meridional potential vorticity gradient in the subtropical upper troposphere that acts to increase the wave number locally. In combination, this creates an equatorward gradient of anomalous wave number between the Subtropics and the midlatitudes that causes eddies to be refracted equatorward (Karoly and Hoskins, 1982; Hoskins and Ambrizzi, 1993; Seager et al., 2003).

\section{Conclusions}

We have examined the influence that ENSO exerts on the mean and transient atmospheric circulation in the Pacific-North America sector using daily reanalysis data, idealized GCM experiments and simulations with a stormtrack model. The goal has been to explain observed changes in the latitude of the Pacific storm track at the western edge of North America, since it is presumed that this helps to explain ENSO-related precipitation anomalies. For example, during El Niño winters the Pacific jet and storm track are southwarddisplaced and eastward-extended and, correspondingly, the southwestern United States, Mexico and the southern United States are wetter than normal while regions to the north are drier than normal. Roughly the opposite situation prevails during La Niña events and, when the La Niñas persist for years, causes the devastating multiyear droughts that trouble southwestern North America. We reach the following conclusions.

- Daily reanalysis data support the concept of a southward-displaced and eastward-extended Pacific storm track during El Niño winters. One-point correlation analysis of upper tropospheric high-passfiltered meridional velocity supports the idea of a more zonal storm track in El Niño winters and a more split track in La Niña winters, with a dominant northeast-trending path.

- Extending the analysis of Chang and Yu (1999), one-point correlation maps were used to compute indices of wave coherence and the speed, direction and amplitude of wave-packet propagation separately for El Niño and La Niña winters. These confirm that El Niño winters feature anomalously strong propagation of transient eddies directly eastward into southwestern North America. In La Niña winters, eastward of the central Pacific there is an anomalously strong path of propagation northeastward towards the Pacific Northwest and an anomalously strong leak of wave energy southeastward towards the equatorial east Pacific.

- These ENSO-related changes in transient eddy propagation in the Pacific-North America sector can be reproduced in 100 day integrations of a GCM subject to an instantaneous turn-on of an El Niño or La Niña SST anomaly on December 1. Since the GCM has climatological SSTs outside the tropical Pacific, the modelled changes in eddy propagation are a response to tropical forcing and do not involve extratropical air-sea interaction.

- To elucidate the mechanisms whereby the Tropics modulate midlatitude eddies (TMME), we use simulations with a nonlinear storm-track model with specified, observed, El Niño and La Niña basic states. The model is run in a time-marching manner and forced by random (in space and time) heating perturbations over Asia that trigger baroclinic instability. The storm-track model is run for 100 days for the El Niño and La Niña basic states. Over the Pacific, the difference between these matches the observed eastward-extended and southwardshifted storm track during El Niño winters and the anomalously strong paths towards the Pacific Northwest and the eastern equatorial Pacific during La Niña winters.

- The results of the models with specified basic states, in so far as they reproduce the observed phenomena, are suggestive of the causes of the changes in the Pacific storm track. Changes in upstream seeding and atmospheric moisture are, for example, ignored in these simulations. Computation of the baroclinic energy conversion in observations and the stormtrack model also suggests that eddy regeneration over the central Pacific (driven by the tropical Pacific warm SST anomaly and warm tropical troposphere during El Niño winters) need not be invoked as a cause (although there is greater baroclinic conversion east of Japan during El Niño winters). This leaves wave refraction as a plausible hypothesis: eddies leaving Asia propagate east through different basic states for El Niño and La Niña winters. The strong subtropical westerly anomalies, equatorward of the climatological jet, during El Niño winters acts as a waveguide that steers eddies into southwestern North America.

- The importance of wave refraction is also suggested by simulations with the storm-track model that use basic states taken from different periods in the transient adjustment simulations with the GCM. The basic pattern of storm-track anomalies is simulated by the storm-track model even when a basic state is imposed that is from a time period in the GCM simulations before eddies significantly modify the mean flow. The storm-track anomalies are stronger when basic states from later periods of the GCM simulations are imposed, suggestive of a positive eddy-mean-flow interaction (Branstator, 1995).

These results remain largely diagnostic. We have not examined the impact that the eddies will have on the mean flow and how the mean and transient flow evolve together. Certainly the direct, Gill-type, response to ENSO SST anomalies will create subtropical westerly wind anomalies that will cause the changes in wave refraction and propagation paths identified here. One question is how the resulting eddy momentum and heat flux anomalies modify the direct, tropically forced, mean-flow anomalies. Further, while we have emphasized the possibility of explaining observed changes in terms of wave refraction, it is also quite likely that changes in seeding, baroclinic energy conversion and wave breaking also play a role (Orlanski, 2005; Shapiro et al., 2001) in establishing the mean and transient circulation response to ENSO. In a follow-up article (Harnik et al., 2010) we will make more use of the large ensembles of seasonal GCM simulations subject to turn-ons of ENSO SST anomalies, together with a simple quasi-geostrophic model of transient eddies, to determine the exact sequence 
of cause and effect in the adjustment of the mean and transient atmospheric circulation. There it will be shown that a cooperative interaction between the mean flow, wave refraction and eddy fluxes, on a time-scale of weeks to months, leads to the establishment, intensification and evolution of the circulation response and its transmission to higher latitudes.

\section{Acknowledgements}

This work was supported by NSF grants ATM08-04107 and ATM05-43256 and NOAA grants NA06OAR4310151, NA03OAR4320179 and NA03OAR4320179. NH was supported by grant 1370/08 from the Israeli Science Foundation. We thank Edmund Chang for useful conversations and two anonymous reviewers for their constructive critiques.

\section{References}

Branstator G. 1995. Organization of storm track anomalies by recurring low-frequency circulation anomalies. J. Atmos. Sci. 52: 207-226.

Chang EKM. 2006. An idealized nonlinear model of the northern hemisphere winter storm tracks. J. Atmos. Sci. 63: 1818-1839.

Chang EKM, Yu DB. 1999. Characteristics of wave packets in the upper troposphere. Part I: northern hemisphere winter. J. Atmos. Sci. 56: 1708-1728.

Chang EKM, Lee S, Swanson KL. 2002. Storm track dynamics. J. Climate 15: $2163-2183$

Compo GP, Sardeshmukh PD. 2004. Storm track predictability on seasonal and decadal timescales. J. Climate 17: 3701-3720.

Cook ER, Seager R, Cane MA, Stahle DW. 2007. North American drought: Reconstruction, causes and consequences. Earth Sci. Rev. 81: 93-134.

Eichler T, Higgins W. 2006. Climatology and ENSO-related variability of North American extratropical cyclone activity. J. Climate 19: 2076-2093.

Gill AE. 1980. Some simple solutions for heat-induced tropical circulations. Q. J. R. Meteorol. Soc. 106: 447-462.

Harnik N, Seager R, Naik N, Cane M, Ting M. 2010. Determining cause and effect in the transient eddy-mean flow response to tropical Pacific SST anomalies. Q. J. R. Meteorol. Soc. Submitted.

Held IM, Lyons SW, Nigam S. 1989. Transients and the extratropical response to El Niño. J. Atmos. Sci. 46: 163-174.

Herweijer C, Seager R, Cook ER. 2006. North American droughts of the mid to late nineteenth century: A history, simulation and implications for Medieval drought. The Holocene 16: 159-171.

Hoerling MP, Ting M. 1994. Organization of extratropical transients during El Niño. J. Climate 7: 745-766.
Hoskins BJ, Ambrizzi T. 1993. Rossby wave propagation on a realistic longitudinally varying flow. J. Atmos. Sci. 50: 1661-1671.

Hoskins BJ, Karoly DJ. 1981. The steady response of a spherical atmosphere to thermal and orographic forcing. J. Atmos. Sci. 38: 1179-1196.

Karoly DJ. 1983. Rossby wave propagation in a barotropic atmosphere. Dyn. Atmos. Oceans 7: 111-125.

Karoly DJ, Hoskins BJ. 1982. Three dimensional propagation of planetary waves. J. Meteorol. Soc. Jpn 60: 109-123.

Kiladis GN, Diaz HF. 1989. Global climatic anomalies associated with extremes in the Southern Oscillation. J. Climate 4: 1069-1090.

Kistler R, et al. 2001. The NCEP-NCAR 50 year reanalysis: Monthly means CD-ROM and documentation. Bull. Am. Meteorol. Soc. 82: $247-268$.

Orlanski I. 2005. A new look at the Pacific storm track variability: Sensitivity to tropical SSTs and to upstream seeding. J. Atmos. Sci. 62: 1367-1390.

Ropelewski CF, Halpert MS. 1987. Global and regional scale precipitation patterns associated with the El Niño/Southern Oscillation. Mon. Weather Rev. 114: 2352-2362.

Ropelewski CF, Halpert MS. 1989. Precipitation patterns associated with the high index phase of the Southern Oscillation. J. Climate 2: $268-284$.

Ropelewski CF, Halpert MS. 1996. Quantifying Southern Oscillation-precipitation relationships. J. Climate 9: 1043-1059.

Schubert SD, Suarez MJ, Pegion PJ, Koster RD, Bacmeister JT. 2004a. On the cause of the 1930s Dust Bowl. Science 303: 1855-1859.

Schubert SD, Suarez MJ, Pegion PJ, Koster RD, Bacmeister JT. 2004b. Causes of long term drought in the United States Great Plains. J. Climate 17: 485-503.

Seager R, Harnik N, Kushnir Y, Robinson W, Miller J. 2003. Mechanisms of hemispherically symmetric climate variability. J. Climate 16: 2960-2978.

Seager R, Harnik N, Robinson WA, Kushnir Y, Ting M, Huang HP Velez J. 2005a. Mechanisms of ENSO-forcing of hemispherically symmetric precipitation variability. Q. J. R. Meteorol. Soc. 131: $1501-1527$.

Seager R, Kushnir Y, Herweijer C, Naik N, Miller J. 2005b. Modeling of tropical forcing of persistent droughts and pluvials over western North America: 1856-2000. J. Climate 18: 4065-4088.

Shapiro MA, Wernli H, Bond NA, Langland R. 2001. The influence of the 1997-99 El Niño-Southern Oscillation on extratropical life cycles over the eastern North Pacific. Q. J. R. Meteorol. Soc. 127: 331-342.

Straus DM, Shukla J. 1997. Variations of midlatitude transient dynamics associated with ENSO. J. Atmos. Sci. 54: 777-790.

Ting M, Yu L. 1998. Steady response to tropical heating in wavy linear and nonlinear baroclinic models. J. Atmos. Sci. 55: 3565-3582.

Trenberth KE, Hurrell JW. 1994. Decadal atmosphere-ocean variations in the Pacific. Clim. Dyn. 9: 303-319.

Zhang Y, Held IM. 1999. A linear stochastic model of a GCM's midlatitude storm tracks. J. Atmos. Sci. 56: 3416-3435. 